Research Article

\title{
Interdecadal Variability of Summer Precipitation Efficiency in East Asia
}

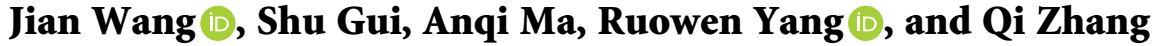 \\ Department of Atmospheric Sciences, Yunnan University, Kunming, China \\ Correspondence should be addressed to Ruowen Yang; yangruowen@ynu.edu.cn
}

Received 22 July 2019; Revised 5 October 2019; Accepted 17 October 2019; Published 4 December 2019

Academic Editor: Jorge E. Gonzalez

Copyright (c) 2019 Jian Wang et al. This is an open access article distributed under the Creative Commons Attribution License, which permits unrestricted use, distribution, and reproduction in any medium, provided the original work is properly cited.

\begin{abstract}
Precipitation efficiency (PE) is a crucial physical quantity in convective processes, describing the efficiency of rainfall generation from cloud detrainment. Although the importance of $\mathrm{PE}$ in extreme precipitation events is widely accepted, the evolution of PE in the warming climate and the associated moisture processes in East Asia are still not well understood. To address these issues, the interdecadal variability of PE in East Asia during summer in 1979-2016 is investigated in this study. Two major modes of summertime precipitation efficiency are identified using Empirical Orthogonal Function (EOF) analysis. The leading EOF mode (EOF1) has a dipole pattern that reveals the variations of mean precipitation efficiency. The second EOF mode (EOF2) presents a quadrupole pattern that shows changes in the variability of precipitation efficiency. Both EOF modes exhibit significant interdecadal variability (IDV). The IDV of EOF1 is closely associated with the phase change of the Pacific decadal oscillation (PDO). The Pacific sea surface temperature anomalies associated with the PDO can excite wind anomalies that significantly modulate moisture transport and further alter the mean precipitation efficiency in East Asia. The IDV of EOF2 can be attributed to the interdecadal change of occurrence frequency of Eastern Pacific El Niño-Southern Oscillation (ENSO) events, which affect water vapor transport by inducing an East Asia-Pacific teleconnection-like wave train anomaly pattern. The IDV patterns of precipitation efficiency for both the mean value and variability will improve the ability to predict precipitation in East Asia.
\end{abstract}

\section{Introduction}

Precipitation efficiency (PE) is an important physical quantity of a convective system that characterizes the efficiency of rainfall generation via water vapor from cloud detrainment. Generally speaking, PE is the ratio of precipitation rate to the condensation of water vapor in the convection process. It incorporates the influence of the detrained water from the convective-scale background on rainfall variations and thus depicts a broader picture of precipitation processes than merely precipitation rate. The $\mathrm{PE}$ is also used in operational rainfall forecasting to determine the intensity and spatial coverage of precipitation events $[1,2]$.

The investigation of $\mathrm{PE}$ can help determine the impact of dynamical and microphysical processes that cause precipitation changes. Early research on PE can be traced back more than half a century [3]. Since then, many studies have explored the spatiotemporal evolution of PE and its impact on weather and climate systems [4-7]. Recently, PE has gained popularity in modeling studies and operational forecasts due to its crucial impact on convective closure, rainfall conversion rate, and convective cloud-climate feedback [8-10]. Previous studies also suggest that climate sensitivity is closely associated with PE in global warming simulations [11-14]. The PE-related uncertainties in future projections of the hydrological cycle also affect aerosol concentrations and optical properties $[15,16]$.

The PE variability is closely associated with rainfall variation and the thermodynamic and radiative properties of the atmosphere at weather and climate scales [17-21]. The moisture source from heat divergence in the thermally related rainfall budget contributes more to precipitation than the source from water vapor convergence in the water vaporrelated rainfall budget. The PE associated with thermal processes is less than that derived from water vapor processes, 
and PE during the development phase of rainfall is higher than that in the decay phase [22]. Previous studies suggest that ice clouds have a significant impact on the organization of tropical convection that affects PE in terms of both microphysical processes and radiative effects [23-25]. The microphysical processes of ice clouds alter the hydrometeor concentration and the atmospheric moistening, while the radiative effects modulate the radiative cooling that affects condensation and the associated latent heat release.

Owing to its direct association with precipitation, $\mathrm{PE}$ is a crucial factor in convective systems and influences the proportion of detrained cloud water, cloud cover, cloud radiative forcing, latent heating, and the large-scale atmospheric circulation [25-27]. Many studies have estimated PE as the precipitation amount divided by the mass of associated moisture sources, but the definition may vary with the specific context of water budget estimation. For example, PE can be defined as the ratio of precipitation rate to the sum of the surface evaporation and water vapor convergence from the perspective of large-scale water vapor budgets [28-30]. It can also be defined as the ratio of precipitation rate to the vertical integral of condensation and deposition rates derived from the cloud microphysical budget $[9,31,32]$. The $\mathrm{PE}$ also serves as a crucial factor in the parameterization of cumulus convection [33-36].

Variations of atmospheric circulation have a significant impact on the water vapor sources of precipitation by altering the moisture transport pathway, convective intensity, and water vapor condensation and deposition in cumulus clouds [23, 24, 37, 38]. The southwesterly winds along the northwest flank of the western Pacific subtropical high (WPSH) have similar effects on rainfall variations in China during both spring and summer [25]. Zhu et al. [27] found a significant decadal change of spring precipitation over southern China that is out of phase with summer precipitation. As a major monsoon system, the East Asian monsoon is an important modulator of the East Asian climate, which shapes the seasonal march of major rain belts and the Meiyu-Baiu rains with its significant variability from intraseasonal to interdecadal scales [26]. It also affects the ENSO-related teleconnections that extend the influence to the global scale [39]. As PE is the reciprocal of atmospheric water residence time, its variability is closely associated with the activity of the East Asia summer monsoon (EASM) $[19,21]$. Wei et al. [29] suggested that different age patterns of tagged precipitation in Southeast China reflect the varying impact of the EASM through prevailing wind directions and wind speeds.

Sea surface temperature anomalies (SSTAs) in the Pacific and Indian Ocean have a large impact on the variability of precipitation and PE [28, 30, 40]. Lau and $\mathrm{Wu}$ [9] suggested that PE in light warm rain increases with increasing SST, but for heavy rain with deep convection, there is no dependence on SST warming. Bosilovich et al. [31] pointed out that the residence time of moisture increases together with total precipitable water, which implies a decreasing trend of global water cycling rate. With increasing water vapor in the lower troposphere, the intensity of moist convection lessens and mass exchange between the boundary layer and the middle troposphere decreases to balance the global hydrological cycle $[32,33]$. $\mathrm{Xu}$ et al. [36] suggested that the interdecadal change in the intensity of spring rainfall variations over southern China can be attributed to the reduced amplitude of SSTAs in the West Pacific after 1996.

Summer precipitation anomalies in East Asia can lead to flood and drought disasters that impact nearly one-third of the world's population and cause great economic damage $[35,36,41,42]$. Although the importance of $\mathrm{PE}$ for the precipitation variability is widely known, previous studies have paid little attention to the spatiotemporal evolution of $\mathrm{PE}$ in East Asia and its relation to atmospheric dynamic and thermodynamic processes. In addition, the asymmetric impact of global warming increases the complexity of PE evolution by intensifying the EASM, which leads to further uncertainties in the future projection of precipitation $[19,20,43]$. To advance our understanding of global warming impacts on East Asian climate change, it is necessary to study the interdecadal evolution of PE as well as its drivers in the climate system. This study focuses on the interdecadal variability (IDV) of summer PE in East Asia, its impact on precipitation patterns, and the underlying mechanisms.

The remainder of this paper is organized as follows. In Section 2, the reanalysis data and methodology are introduced. In Section 3, the climatology and the IDV characteristics of PE in East Asia are analyzed. In Section 4, the primary cause of mean precipitation IDV is analyzed via analysis of the SST and the associated atmospheric response. An analysis of the causes of precipitation IDV is presented in Section 5. Finally, a summary and discussion are given in Section 6.

\section{Data and Methods}

2.1. Data. The ERA-Interim monthly reanalysis data from the European Centre for Medium-Range Weather Forecasts (ECMWF), including surface pressure, specific humidity, geopotential height, and atmospheric winds, are used at $0.5^{\circ}$ horizontal resolution and 37 pressure levels $[44,45]$. Two versions of monthly mean precipitation data are used in this study: one from the Global Precipitation Climatology Project (GPCP) version 2 with a horizontal resolution of $2.5^{\circ}$ and the other from the Global Precipitation Climatology Center (GPCC) version 8 with a horizontal resolution of $0.5^{\circ}$. In addition, we use monthly SST data from the Extended Reconstruction SSTs (ERSSTs) version 5 of the National Oceanic and Atmospheric Administration (NOAA) with $2^{\circ}$ horizontal resolution [46]. The ERSST data have been widely used in a number of climate studies related to the interdecadal SST variabilities [47-51], which is suitable for our present study on interdecadal timescale and large spatial coverage. All datasets used in this study cover the period 1979-2016.

\subsection{Methods}

2.2.1. Precipitation Efficiency. Following Huang et al. [52], the precipitation efficiency (PE) is defined as the 
precipitation amount $(P)$ divided by the total amount of precipitable water $(Q)$ in the atmosphere:

$$
\mathrm{PE}=\frac{P}{\mathrm{Q}} \text {. }
$$

It is the reciprocal of the atmospheric water residence time defined by Ent and Tuinenburg [18]. This PE formula resembles other definitions of large-scale precipitation efficiency (LSPE) in previous studies [53, 54]. Since Student's $t$-test is one of the most popular test methods for studies of interdecadal variations and long-term trends of the climate system [55-59], we use this test method to establish the significance of PE and related physical fields.

2.2.2. Niño Indices. Two Niño indices developed by Ren and Jin [60] are adopted to differentiate the warm-pool (WP) and cold-tongue (CT) types of ENSO events. The two Niño indices are defined as follows:

$$
\begin{gathered}
\left\{\begin{array}{l}
I_{\mathrm{EPI}}=N_{3}-\alpha N_{4}, \\
I_{\mathrm{CPI}}=N_{4}-\alpha N_{3},
\end{array}\right. \\
\alpha= \begin{cases}\frac{2}{5}, & N_{3} N_{4}>0, \\
0, & N_{3} N_{4} \leq 0,\end{cases}
\end{gathered}
$$

where $I_{\mathrm{EPI}}$ denotes the eastern-type (CT type) index and $I_{\mathrm{CPI}}$ is the central-type (WP type) index. $N_{3}$ and $N_{4}$ represent the Niño3 and Niño4 indices, respectively. $N_{3}$ indices are obtained by averaging the monthly SST anomalies over $150^{\circ} \mathrm{W}-90^{\circ} \mathrm{W}, 5^{\circ} \mathrm{S}-5^{\circ} \mathrm{N}$, where anomalies are defined relative to the climatology of the research period. $N_{4}$ indices are calculated in the same manner with SST anomalies averaged across $160^{\circ} \mathrm{E}-150^{\circ} \mathrm{W}, 5^{\circ} \mathrm{S}-5^{\circ} \mathrm{N}$. $I_{\mathrm{EPI}}$ is calculated with the ERSST monthly data to quantitatively determine the occurrence rate of EP-type ENSO events, which facilitates investigation of the impact of eastern-type ENSO events on the IDV of summer PE. The eastern-type El Niño (La Niña) is defined under the condition that $I_{\mathrm{EPI}}$ is greater (less) than $0.5^{\circ} \mathrm{C}\left(-0.5^{\circ} \mathrm{C}\right)$ for 6 consecutive months.

2.2.3. EOF Analysis. Lorenz [61] proposed the Empirical Orthogonal Function (EOF) method for representing pressure and temperature fields in statistical weather prediction. It is also known as principal component analysis (PCA) in statistics. EOF analysis is often used to investigate the spatial patterns and temporal variabilities of meteorological fields $[62,63]$. This analysis method computes the eigenvalues and eigenvectors of a spatially weighted anomaly covariance matrix of a physical field and yields the EOFs that are mathematically orthogonal (independent) modes. The explained variance for each mode is the ratio between the variance of that principal component and the total variance. The significance test for the uniqueness of each EOF mode is carried out based on the "Rule of Thumb" criterion of North et al. [64]. If the sampling error of eigenvalue $\lambda$ is larger than or comparable to the spacing to the neighboring eigenvalue, then the corresponding EOF mode is not separable from others. The detailed mathematical derivation and discussion of this analysis method are well documented in statistics and mathematics textbooks $[62,63]$. The $F$-test is employed to examine the significance of interdecadal variability in the time series of each EOF mode, in which the ratio of two variances is compared with the $95 \%$ threshold.

\section{Climatology and Interdecadal Variability of Precipitation Efficiency}

3.1. PE Climatology. The summer mean total precipitable water, precipitation amount, and PE in East Asia are presented in Figure 1. Total precipitable water and precipitation exhibit similar spatial patterns, with high values in Southeast Asia. However, the local PE is generally smaller there than in central China and the Korean Peninsula. The maximum values of $\mathrm{PE}$ are scattered around the periphery of the East Asian domain, including Southwest Japan, the Korean Peninsula, the eastern part of the Russian Far East, and western China. Minimum PE values are located around the central and western parts of the Mongolian Plateau. The total precipitable water in Southeast Asia exceeds $42.5 \mathrm{~mm} / \mathrm{d}$, denoting sufficient moisture supply with intensive convective activity, which leads to large amounts of rainfall of over $4 \mathrm{~mm} / \mathrm{d}$. In most parts of East Asia, PE is less than 15\%. As the precipitation gradually decreases northward, PE falls to $5 \%-15 \%$ in northern China and further reduces to the minimum value $(<5 \%)$ in central Mongolia, where the total precipitable water is also at its lowest level, $12.5-20.0 \mathrm{~mm} / \mathrm{d}$.

The range of fluctuation of total precipitable water, precipitation, and $\mathrm{PE}$ may be quantified in terms of the standard deviation (Figures $1(\mathrm{~d})-1(\mathrm{f})$ ). There are obvious differences between the patterns of fluctuation for total precipitable water and precipitation in Southeast China. The spatial distribution of the PE standard deviation shows large variability in the western Sichuan basin, southeast coast of China, southwestern Japan, Korean Peninsula, northeastern China, and the eastern part of the Russian Far East. The PE variabilities in the southern and western Mongolian plateau are the smallest in the research domain. We calculated the pattern correlations for the variations of total precipitable water, precipitation, and PE to quantitatively compare their similarities. The pattern correlation is the Pearson productmoment coefficient of linear correlation between the two fields shown in Figures 1(d)-1(f). The pattern correlation between $\mathrm{PE}$ and precipitation is 0.788 , much higher than that between PE and total precipitable water $(-0.373)$, suggesting that the precipitation variability has a major influence on PE variability in summer.

3.2. Interdecadal Variability of PE. To determine the dominant patterns of PE IDV, we applied the Empirical Orthogonal Function (EOF) analysis to the summer (JuneAugust) average PE in East Asia. The explained variances of the first two EOFs are well above those of the other EOFs 


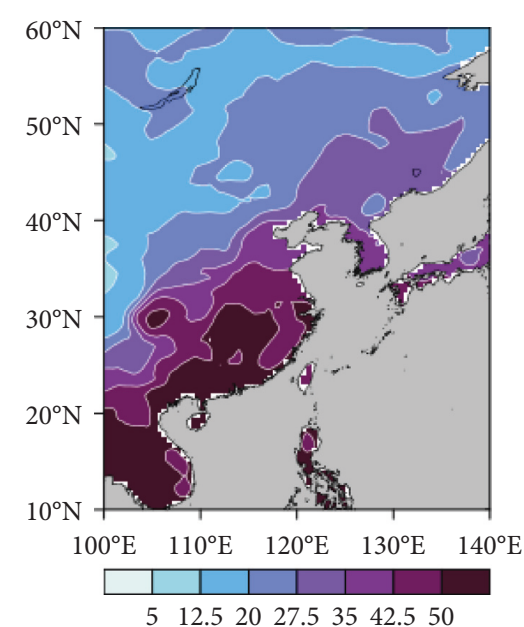

(a)

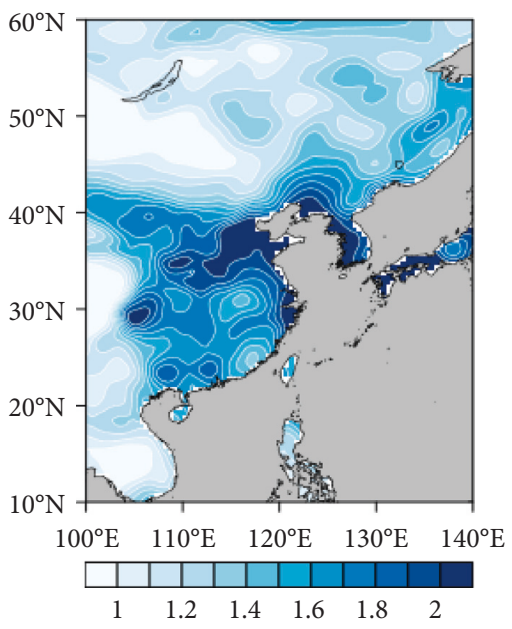

(d)

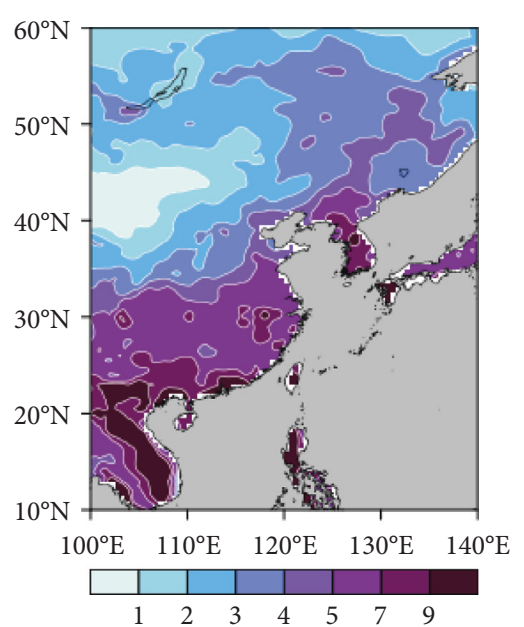

(b)

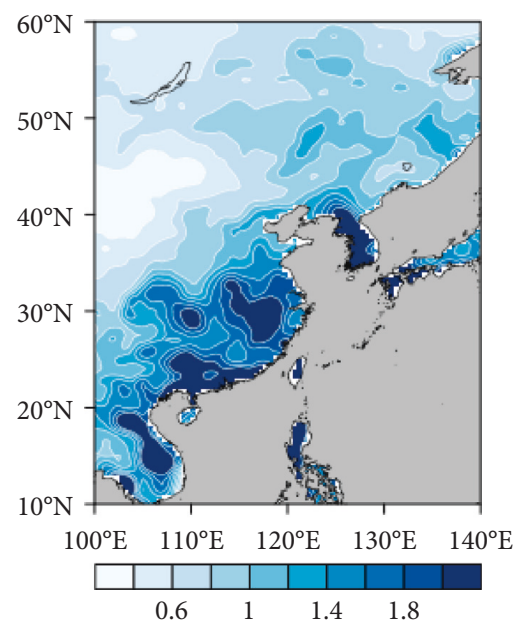

(e)

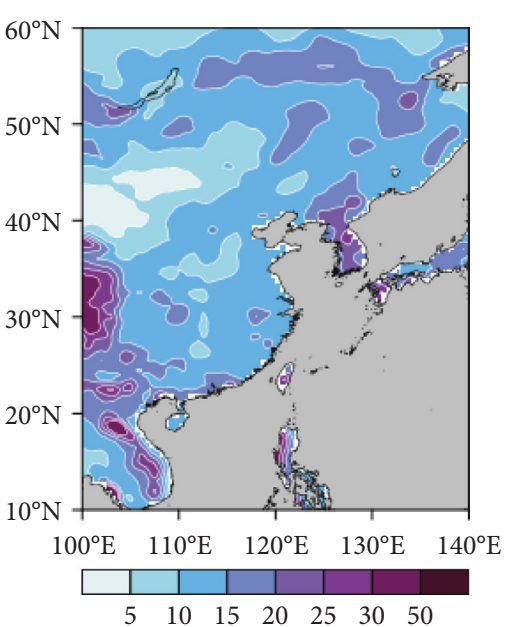

(c)

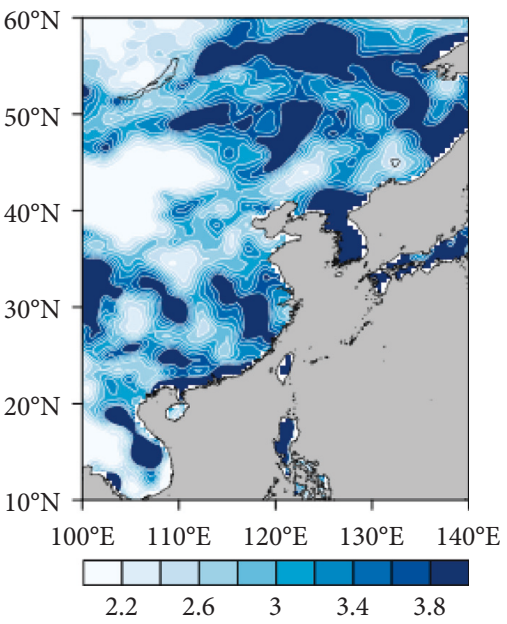

(f)

FIGURE 1: Spatial distributions of (a) mean total precipitable water ( $\mathrm{mm} / \mathrm{d}),(\mathrm{b})$ mean precipitation $(\mathrm{mm} / \mathrm{d})$, (c) mean precipitation efficiency (\%), and the standard deviations of (d) total precipitable water, (e) precipitation, and (f) precipitation efficiency in boreal summer during 1979-2016.

(15.36\% for EOF1, $10.00 \%$ for EOF2, 6.32\% for EOF3, and $5.41 \%$ for EOF4). In addition, the EOF1 and EOF2 are well separated from each other based on the North significance test, which uses the "Rule of Thumb" criterion to determine the uniqueness of each EOF mode [52]. Therefore, the analysis of PE IDV focuses on the two leading EOFs.

3.2.1. EOF1. The EOF1 presents a dipole pattern with a positive center around the region where China, Mongolia, and Russia meet and a negative center in Southeast China (Figure 2(b)). The separatrix of the dipole pattern is located around $35^{\circ} \mathrm{N}$, which implies inverse variations of $\mathrm{PE}$ in the northern and southern parts of East Asia. There is a remarkable rising trend in the first principal component (PC1) on an interdecadal scale, in which the time series is generally negative (positive) during 1983-1998 (1999-2011). This IDV can be seen clearly from the changes in mean value between the two periods (Figure 2(a)). The mean value of PC1 during the first (second) period is $-0.616(0.772)$. The difference between the two periods is statistically significant at the $99 \%$ level (Student's $t$-test). This suggests that the mean value of PC1 exhibits remarkable IDV, with EOF1 varying from the negative-positive dipole pattern during 1983-1998 to the positive-negative dipole pattern during 1999-2011.

We further examine the significance of the IDV of PC1 variability by dividing PC1 into two sections using a number of separation points. Since one period of IDV is usually longer than 11 years, the separatrix of two periods should lie between the first 12 years and the last 12 years. Thus, we partitioned the PC1 time series by sliding the change point from 1990 to 2005 . This gives a total of 16 partitions as follows: 1979-1990 and 1991-2016, 1979-1991 and 19922016, . . , 1979-2004 and 2005-2016, and 1979-2005 and 2006-2016. The IDV of PC1 variability is determined by analysis of variance (ANOVA) that compares the ratio of two variances ( $F$-statistic) for each partition set with the $95 \%$ threshold. It turns out that none of the partitions passes the significance test (Figure 2(c)), suggesting that the IDV of PC1 variability is insignificant during 1979-2016. 


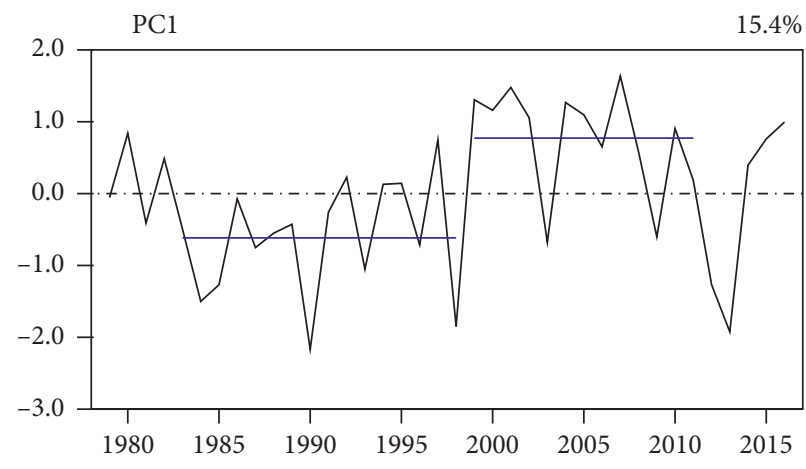

(a)

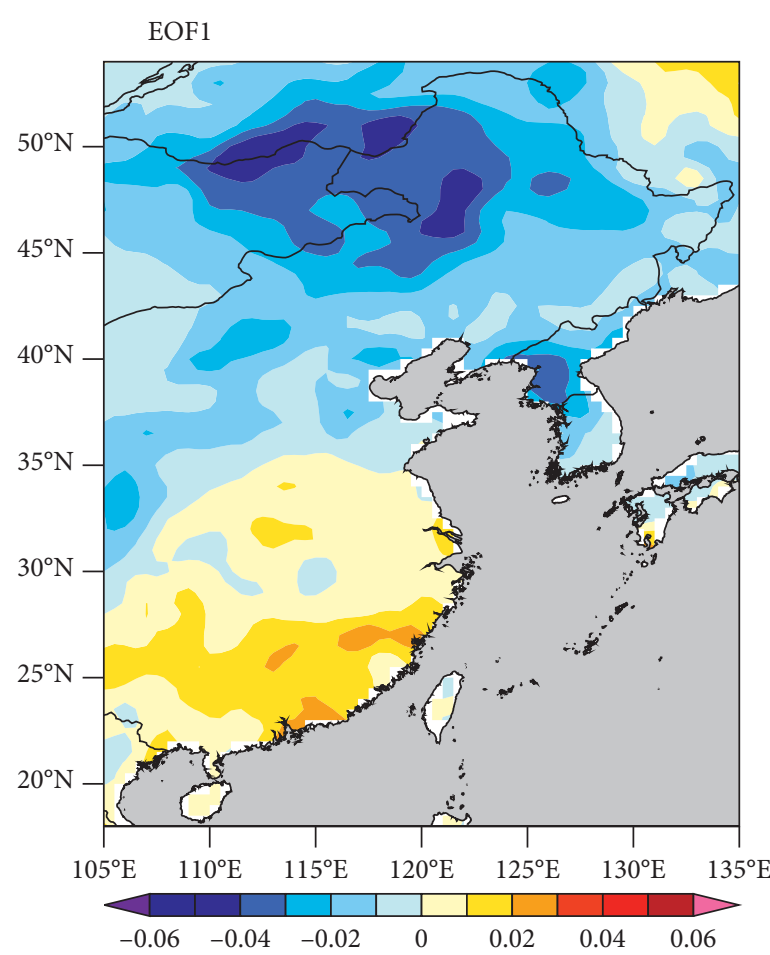

(b)

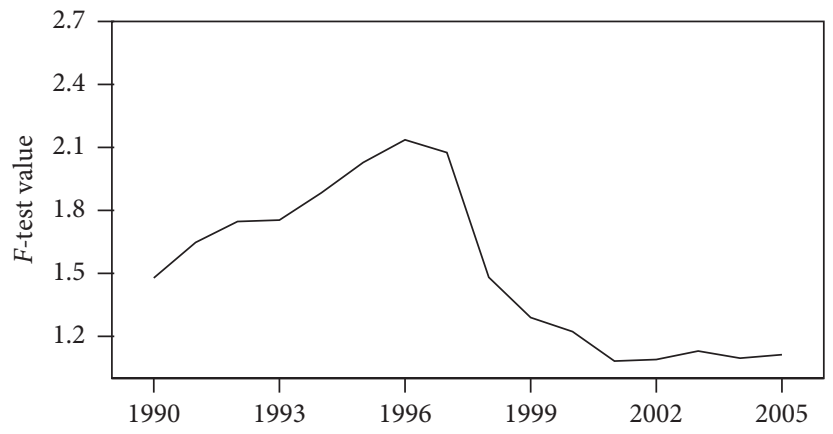

(c)

Figure 2: Normalized time series of the EOF1 (PC1) of the summer mean precipitation efficiency in East Asia during 1979-2016 (a), the spatial distribution of the EOF1 (b), and analysis of variance of PC1 variability (c). The percentage value at the top right in (a) denotes the explained variance of EOF1. Blue solid lines in (a) represent the abrupt changes in mean value between 1983-1998 and 1999-2013, and the dashed line is the zero baseline.

3.2.2. EOF2. The EOF2 exhibits a quadrupole structure with a meridionally negative-positive-negative-positive distribution from south to north with separatrices around $25^{\circ} \mathrm{N}, 35^{\circ} \mathrm{N}$, and $43^{\circ} \mathrm{N}$ (Figure $3(\mathrm{~b})$ ). This implies that PE variations in China's Jianghuai River Basin and Northeast China are the opposite of those in southeastern and northern China. When PE increases around the positive poles, $\mathrm{PE}$ around the negative poles will decrease, and vice versa. There is a transition in the second principal component (PC2) around 1997-1998, with a positive mean value of 0.07 during the period 1979-1997 and a negative mean value of -0.07 during 1998-2016 (Figure 3(a)). However, the mean value of the difference between the two periods is not statistically significant at the $90 \%$ confidence level (figure omitted). This implies that the IDV of PC2 mean value is insignificant.
To further examine the significance of interdecadal signals in PC2 variability, PC2 is divided into 16 groups of partitions in the same way as for PC1. The IDV of PC2 variability is examined using the $F$-test throughout the research time period. The $F$-statistic values exceed the 95\% threshold in 1994, 1995, and 1999, with the maximum value in 1999 (Figure 3(c)). The results indicate that the variability of PC2 IDV has changed in 1999, with larger (smaller) variability during the period 1979-1999 (1999-2016). Changes in the quadruple pattern affect the spatial distribution of precipitation efficiency in East Asia. When it diminishes in the second period, the related PE variations around the anomaly centers also decrease. Thus, the IDV of PC2 variability reveals stronger (weaker) PE variations around the four anomaly centers during 1979-1999 (2000-2016). 


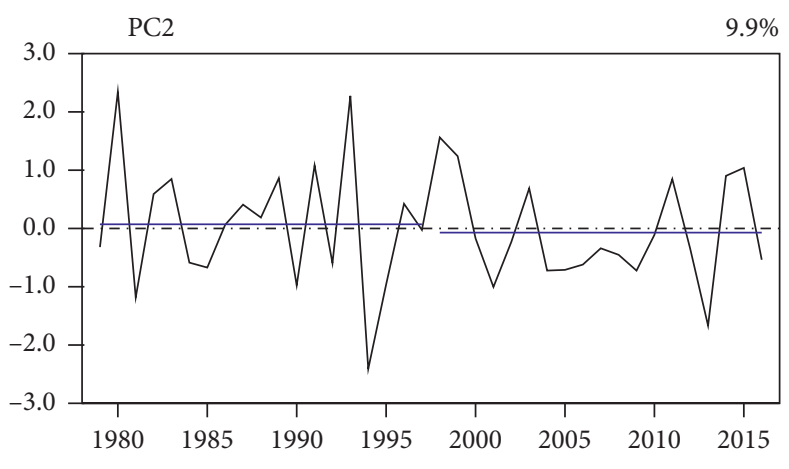

(a)

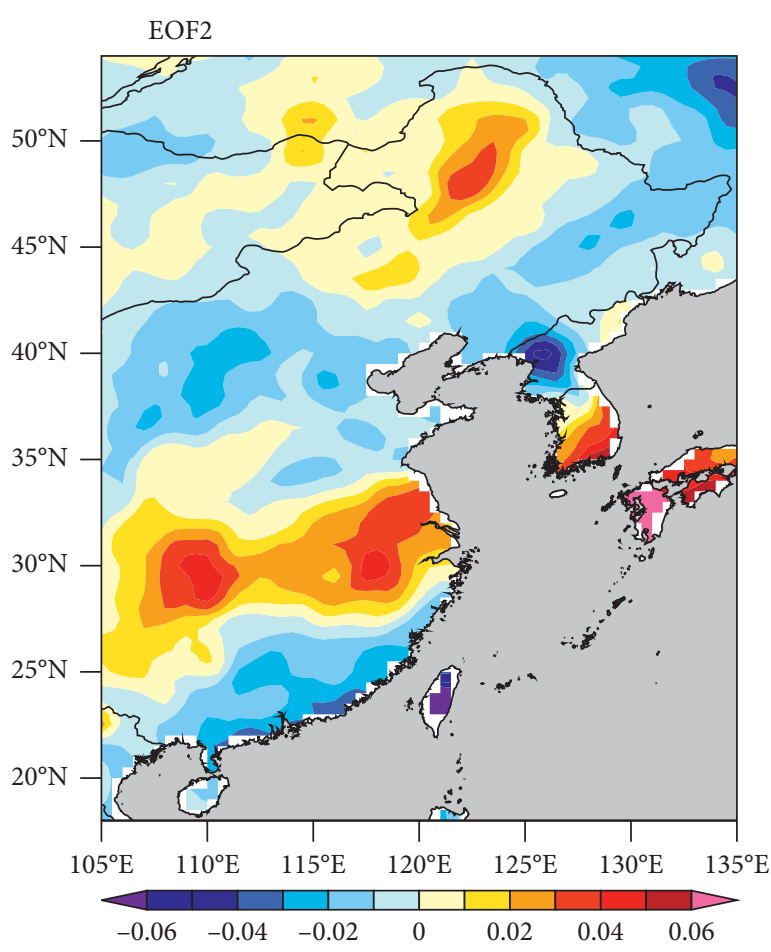

(b)

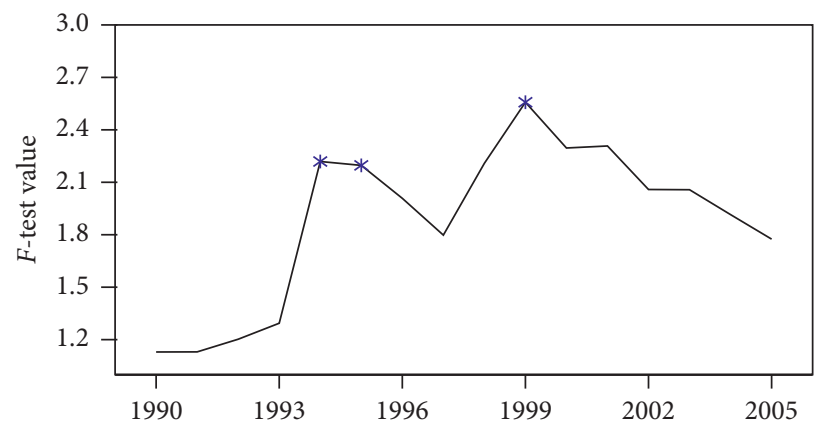

(c)

Figure 3: Normalized PC2 time series of the summer mean precipitation efficiency in East Asia during 1979-2016 (a), spatial distribution of EOF2 (b), and analysis of variance on PC2 variability (c). The percentage value at the top right in (a) denotes the explained variance of EOF2. Blue solid lines in (a) represent the abrupt change in mean value between 1979-1997 and 1998-2016, and the dashed line is the zero baseline. Significant PC2 variabilities in (c) are marked with blue asterisks.

\section{Interdecadal Variability of Mean Precipitation Efficiency}

4.1. Effects of the PDO. Previous studies have shown that SST plays an important role in regulating the East Asian summer climate [53-56] and the interdecadal variations of precipitation over South China [40]. Therefore, we investigate the differences in SST fields between the two periods of PC1 as the first step to reveal the physical mechanisms behind the IDV of mean PE. The SST differences between 1999-2011 and 1983-1998 from the last autumn to summer are presented in Figure 4. Judging from the SST differences between the two periods, it is clear that the global ocean has undergone significant changes above the 95\% confidence level in mean SST. The SST anomalies in winter resemble the PDO pattern during the cool phase [65]. There are significant positive anomalies over the equatorial West Pacific, Northwest Pacific, Southeast Pacific, North Atlantic, and North Indian Ocean, accompanied by remarkable negative anomalies over the eastern Pacific. In summer, the SST anomalies are still warmer in the equatorial West Pacific, Northwest Pacific, Southeast Pacific, North Atlantic, and North Indian Ocean, whereas they are still cooler in the equatorial East Pacific. The SST differences between 1999-2011 and 1983-1998 resemble the PDO pattern during the cool phase. Besides, the observed PDO regime shift is also apparent around 1999 [66-68], from the previous warm phase to the next cold phase. Since the SST differences between the two periods of PC1 IDV coincide well with the observed PDO regime shift, the PC1 IDV may be closely related to the PDO. 


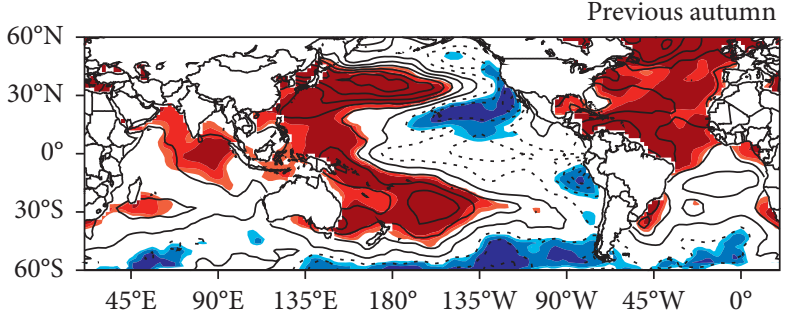

(a)

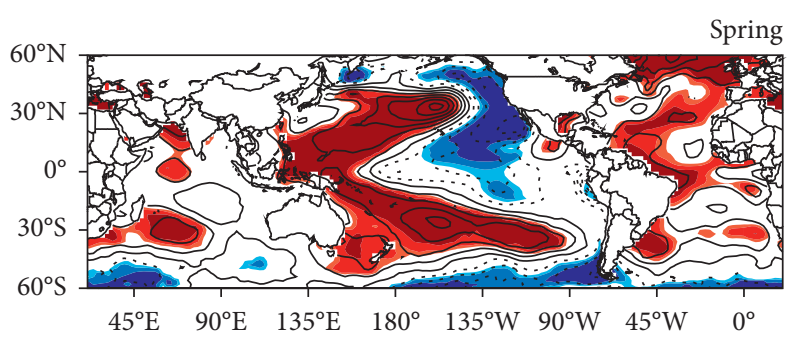

(c)

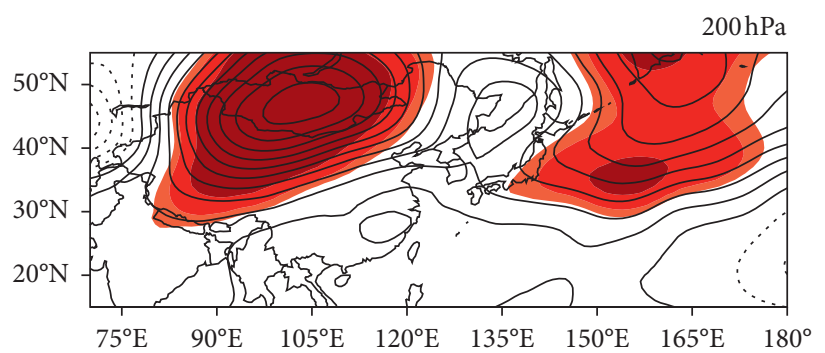

(e)

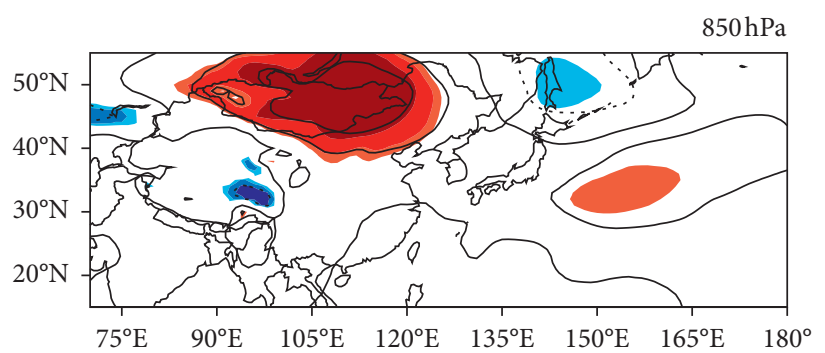

(g)

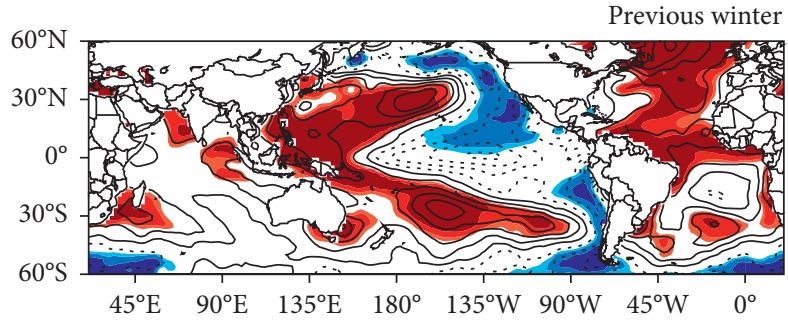

(b)

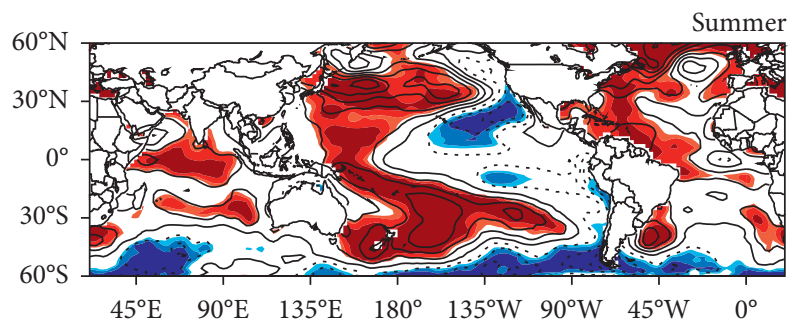

(d)

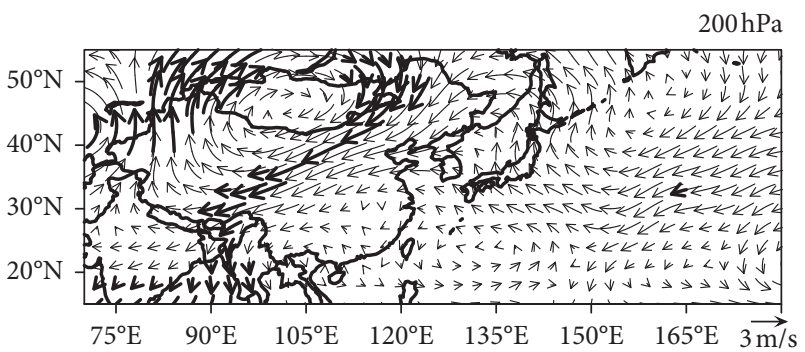

(f)

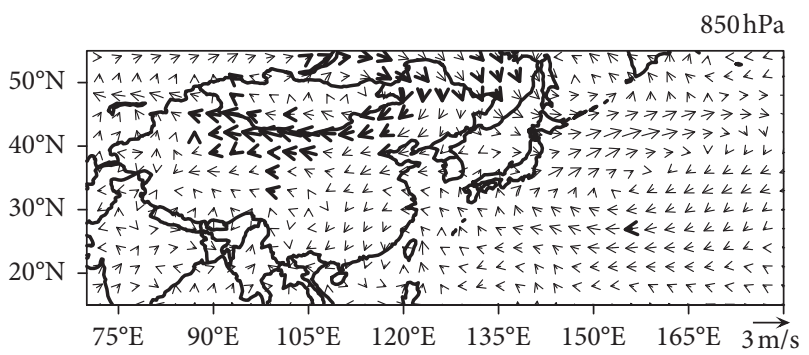

(h)

FIGURE 4: Differences in SST between 1999-2011 and 1983-1998 in the previous autumn (a), previous winter (b), spring (c), and summer (d) (contour interval: $0.2^{\circ} \mathrm{C}$ ). Previous autumn and winter denote the seasons before one year, which means the SST differences in autumn and winter between 1998-2010 and 1982-1997, respectively. Differences in geopotential height (contour interval: 5 gpdm) and horizontal winds in boreal summer between 1999-2011 and 1983-1998 at $200 \mathrm{hPa}(\mathrm{e}, \mathrm{f})$ and $850 \mathrm{hPa}(\mathrm{g}, \mathrm{h})$. Solid (dashed) contours denote positive (negative) anomalies and thick solid lines denote zero. Red (blue) color shadings from light to dark indicate statistical significance at the $90 \%, 95 \%$, and 99\% levels. Thick vectors in (f) and (h) denote statistical significance at the $95 \%$ level.

To further verify this inference, we compare the mean PDO index (PDOI) values between 1983-1998 and 19992011 and carry out a significance test (Student's $t$-test) on the PDOI. The mean PDO index (PDOI) in winter is 1.2281 (-0.2177) during 1983-1998 (1999-2011). Although the difference between the two periods fails the significance test, it is clear that the PDO generally remains in a positive phase during 1983-1998 but moves to a negative phase during 1999-2011. The average PDOIs in spring between the two periods are significantly different at the $95 \%$ confidence level, with mean values of 3.0113 during 1983-1998 and 0.0608 during 1999-2011. The PDOIs exhibit larger differences in summer, with a mean value of $2.8088(-0.9285)$ during 1983-1998 (1999-2011), which pass the 99\% significance test. Results indicate that the PDO has undergone a significant regime shift between the two periods of PC1 IDV, which supports the inference that the PC1 IDV is closely related to the $\mathrm{PDO}$. It also implies that the $\mathrm{PDO}$ phase change is an important factor for the IDV of PC1 mean value. 
4.2. Atmospheric Response to PDOAnomalies. Since the PDO phase change is an important factor for the PC1 IDV, the corresponding spatial pattern of EOF1 is also closely related to the PDO. Changes in geopotential height and horizontal winds at low and high levels of the troposphere are shown in Figure 4. There are prominent positive geopotential anomalies at $200 \mathrm{hPa}$ covering vast areas north of $30^{\circ} \mathrm{N}$ in East Asia. The center of positive anomalies surrounded by dense contours is located in Mongolia. Intensive anticyclonic anomalies appear over the same region, causing northeasterly anomalies in Northeast China. Cyclonic anomalies over South China are weak and statistically insignificant. Geopotential anomalies and wind anomalies at 500,700 , and $850 \mathrm{hPa}$ resemble their counterparts at $200 \mathrm{hPa}$ (Figures 4(c)-4(h)), implying a barotropic structure that dominates the changes in atmospheric circulation associated with the PDO phase change.

Differences between 1999-2011 and 1983-1988 in the column-integrated water vapor flux and its divergence, total precipitable water, precipitation, and $\mathrm{PE}$ in summer are presented in Figure 5. The column-integrated water vapor flux shows an anticyclonic transport that increases the local moisture flux divergence and reduces the total precipitable water and precipitation. These changes in the amount and distribution of atmospheric moisture lead to a significant decrease of PE in Northeast China and Mongolia. South of $35^{\circ} \mathrm{N}$, precipitation, and $\mathrm{PE}$ exhibit opposite variations to their northward counterparts, with total precipitable water still decreasing, although all of these changes are statistically insignificant. The spatial distribution of the PE difference has a center near the north pole of the EOF1 dipole. The results suggest that the atmospheric response to the PDO phase change leads to the IDV of mean PE in East Asia.

\section{Interdecadal Variability of Precipitation Efficiency Variability}

5.1. SST Patterns and the Atmospheric Response during 1979-1999. Since PC2 shows distinct variability before and after the IDV phase change, regression analysis is used to search for the link between PC2 IDV and SST. The PC2regressed SST pattern shows positive anomalies over the equatorial eastern Pacific, which develop consistently from winter to summer during 1979-1999 (Figures 6(b)-6(d)). This variation pattern resembles the equatorial Pacific (EP) type ENSO event that has maximum SST over the equatorial eastern Pacific [69-71]. The SST anomalies in other parts of the global ocean tend to vary considerably from winter to summer, which can be seen as seasonal and intraseasonal disturbances. The results indicate that the EOF2 is in its positive phase with the negative-positive-negative-positive quadrupole structure from south to north during the EPtype El Niño. The signs of the quadrupole reverse during the EP-type La Niña.

The atmospheric response to the EP-type El Niño in the lower and upper troposphere is shown in Figures 6(e)-6(h). The PC2-regressed geopotential height at $200 \mathrm{hPa}$ shows negative anomalies over the Yellow Sea and Bohai Sea and over the eastern Pamir Plateau in Tajikistan, surrounded by positive anomalies in Southeast Asia and parts of the Russian Far East. Variations of atmospheric circulation are consistent with the geopotential anomalies, with a large cyclonic circulation over the Korean Peninsula and eastern Pamir, accompanied by an anticyclonic circulation over the southeast coast of China and the East China Sea (Figure 6(f)). In the lower troposphere, the negative geopotential anomalies are intensified over the Yellow Sea, with positive geopotential anomalies in surrounding areas (Figures 6(e)-6(g)). The atmospheric circulation at different levels generally maintains the same anomalous pattern (Figures 6(f)-6(h)), indicating that the atmospheric response is mainly barotropic. The geopotential height anomalies resemble the wave train of East Asia-Pacific (EAP) teleconnection $[72,73]$, with positive centers over the South China Sea and the eastern part of the Russian Far East and a negative center over the Korean Peninsula. Geopotential anomalies are consistent with the horizontal wind variations that modulate the spatial distribution and transport pathways of atmospheric water vapor in East Asia.

The effects of atmospheric circulation anomalies on PE can be determined by regressing PC2 onto related physical fields, including the column-integrated water vapor flux and its divergence, total precipitable water, precipitation, and PE (Figure 7). The column-integrated moisture flux exhibits anticyclonic anomalies over the southeast coast of China and the South China Sea, which strengthen the local water vapor divergence and result in a decrease in the total precipitable water and precipitation. Because the decrease in precipitation is larger than the decrease in total precipitable water, $\mathrm{PE}$ is reduced accordingly around the southeast coast of China (Figure 7(e)). The water vapor transport is enhanced around the Jianghuai River Basin as a result of the anticyclonic anomalies over the South China Sea. Both precipitation and total precipitable water increase significantly, but the increment of precipitation is obviously larger, leading to a significant increase in PE. The cyclonic circulation over the Korean Peninsula inhibits moisture transport to North China, which enhances the water vapor divergence and reduces the precipitation and total precipitable water over the area. The reduction in total precipitable water is obviously larger than that of precipitation, so PE becomes smaller. For the same reason, PE increases over Northeast China. The above analysis indicates that the atmospheric response to EP-type ENSO results in the quadrupole pattern of PE variability.

5.2. SST Patterns and the Atmospheric Response during 2000-2016. The PC2-regressed SST from the previous winter to summer during 2000-2016 is shown in Figure 8. During autumn and winter, the SST variations over the equatorial Pacific are weak (Figures $8(\mathrm{a})$ and $8(\mathrm{~b})$ ) and are statistically insignificant even at the $90 \%$ confidence level based on Student's $t$-test. Significant positive anomalies develop over the central equatorial Pacific in spring, accompanied by strong negative anomalies over the equatorial western Pacific. Nevertheless, these SST anomalies over the central and western parts of the equatorial Pacific are smaller 


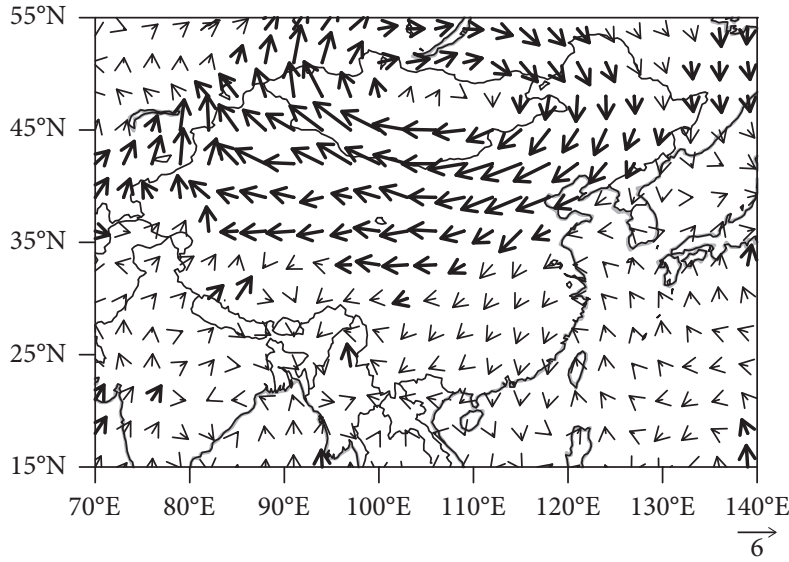

(a)

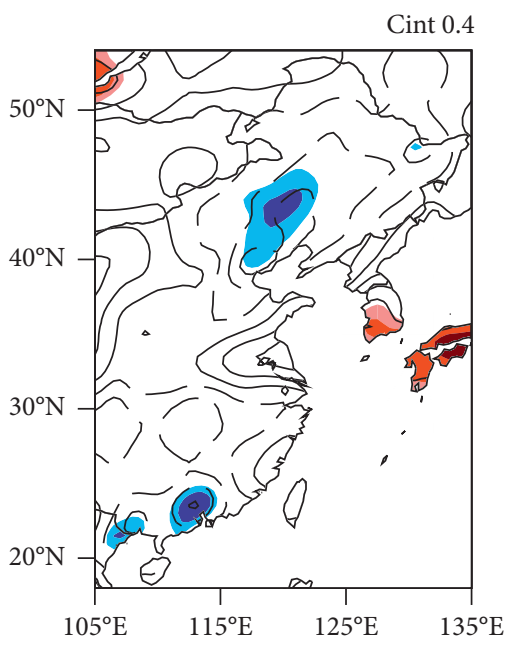

(c)

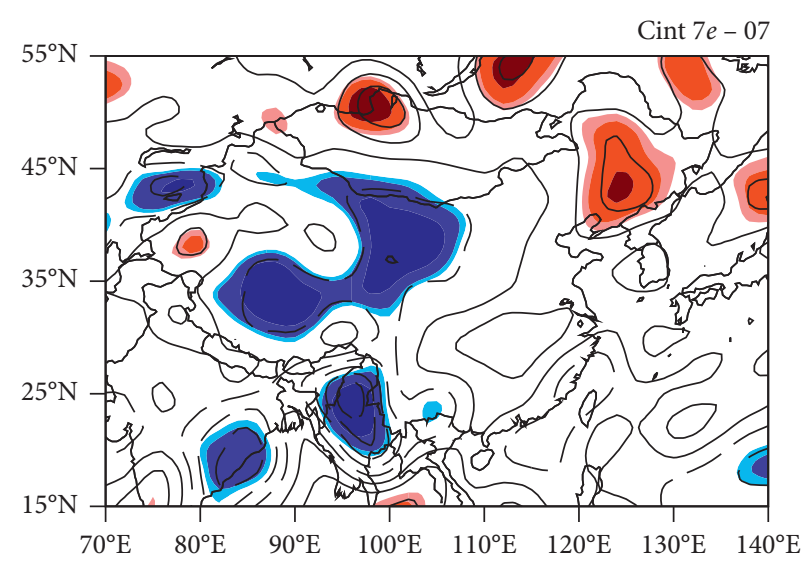

(b)

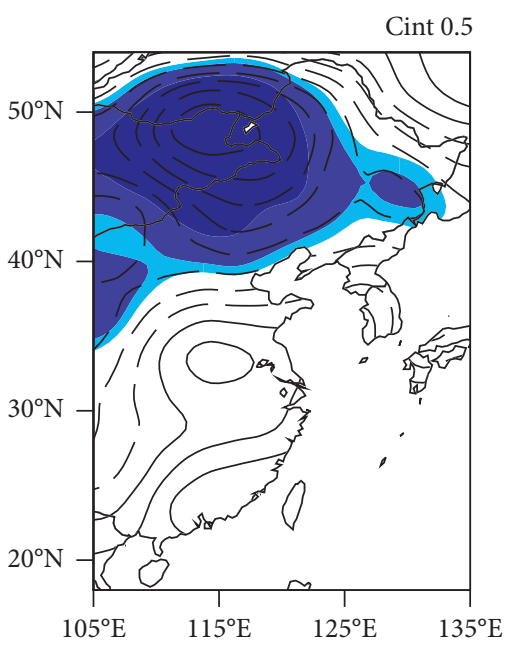

(e)

Figure 5: Differences of column-integrated water vapor flux $(\mathrm{kg} / \mathrm{m} / \mathrm{s} / \mathrm{hPa})(\mathrm{a})$ and its divergence $\left(\mathrm{kg} / \mathrm{m}^{2} / \mathrm{s} / \mathrm{hPa}\right)(\mathrm{b})$, total precipitable water $(\mathrm{mm} / \mathrm{d})(\mathrm{c})$, precipitation $(\mathrm{mm} / \mathrm{d})(\mathrm{d})$, and precipitation efficiency $(\%)(\mathrm{e})$ in summer between 1999-2011 and 1983-1998. Thick vectors in (a) denote statistical significance at the $95 \%$ level. Solid (dashed) contours denote positive (negative) anomalies, and red (blue) color shadings from light to dark indicate statistical significance at the $90 \%, 95 \%$, and $99 \%$ levels.

in summer, and positive anomalies appear over the equatorial eastern Pacific. This implies that the PC2-related El Niño events during 2000-2016 are not of the EP type, which do not have an SST signature until summer. Since the PC2 IDV shows a downward trend, it also suggests that $\mathrm{PE}$ decreases when the SST exhibits a non-EP-type ENSO pattern.

The PC2-regressed geopotential height shows only one significant negative anomaly centered over North China at $200 \mathrm{hPa}$, accompanied by a large-scale cyclonic (anticyclonic) circulation north (south) of $30^{\circ} \mathrm{N}$ (Figures $8(\mathrm{e})$ and $8(\mathrm{f}))$. The negative anomaly center moves southeastward at $500 \mathrm{hPa}$, with expanding positive anomalies over Kazakhstan and the Indo-China peninsula. The atmospheric circulation is dominated by a large-scale anticyclonic circulation centered over the Yellow Sea. At lower levels, the negative geopotential anomaly gradually weakens and the positive anomalies over the Tibetan Plateau and the Russian
Far East continue to strengthen (Figures $8(\mathrm{~g})$ and $8(\mathrm{~h})$ ). The associated cyclonic circulation over the Yellow Sea also weakens and moves southward to the East China Sea. There is no sign of the EAP wave train seen during 1979-1999 from lower to upper levels of the troposphere.

The PC2-regressed column-integrated water vapor flux shows a prominent cyclonic circulation over the East China Sea, which increases the moisture divergence in North China and the water vapor transport to the Jianghuai River Basin (Figure 9). Consequently, the total precipitable water and precipitation decrease (increase) over most parts of North (South) China. The PE shows a similar spatial pattern, which is nevertheless statistically insignificant. The results suggest that the non-EP-type SST anomalies fail to excite the EAP teleconnection that is crucial for developing the quadrupole pattern of EOF2.

The above results show that the SST pattern associated with the PC2 variability resembles the EP-type ENSO 


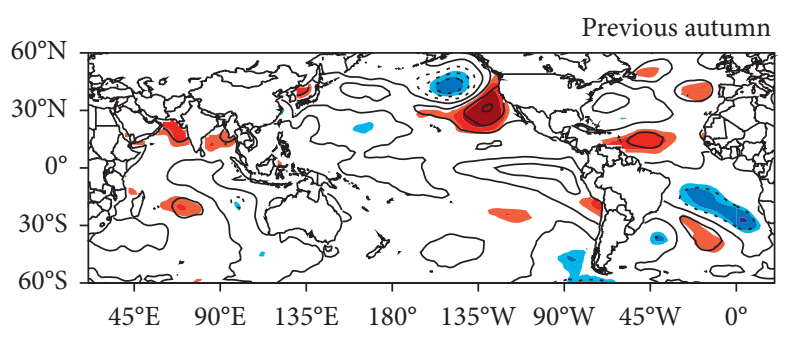

(a)

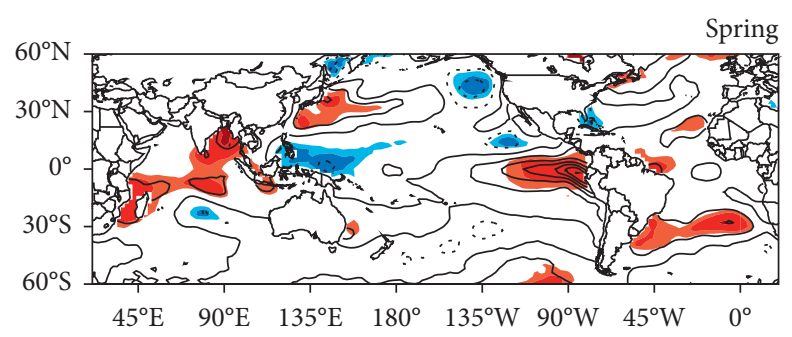

(c)

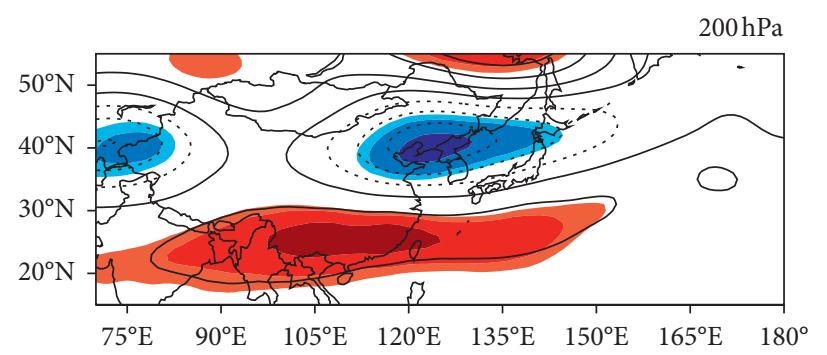

(e)

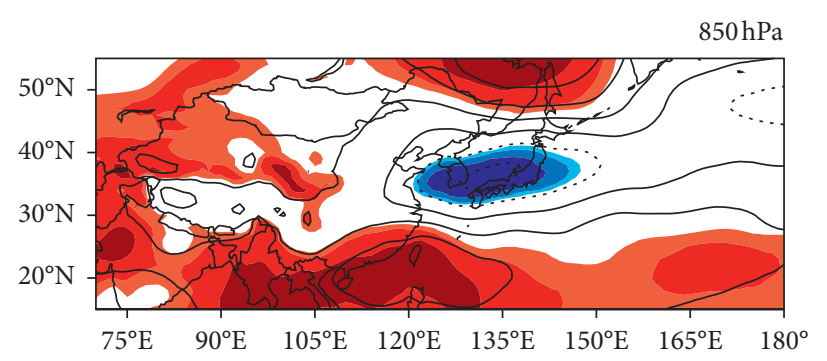

(g)

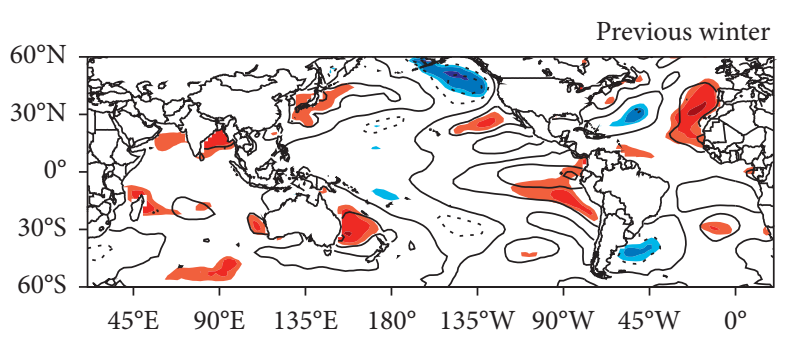

(b)

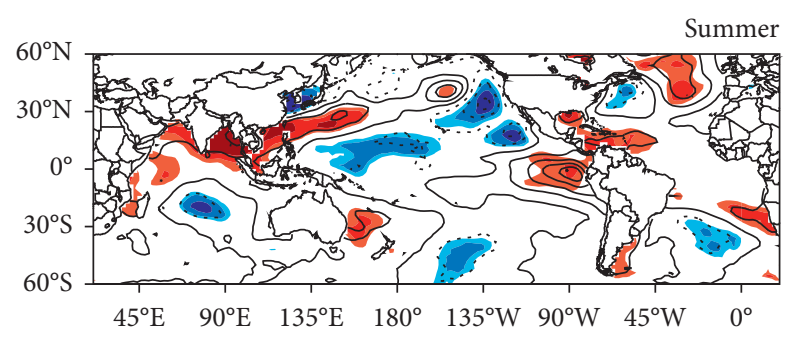

(d)

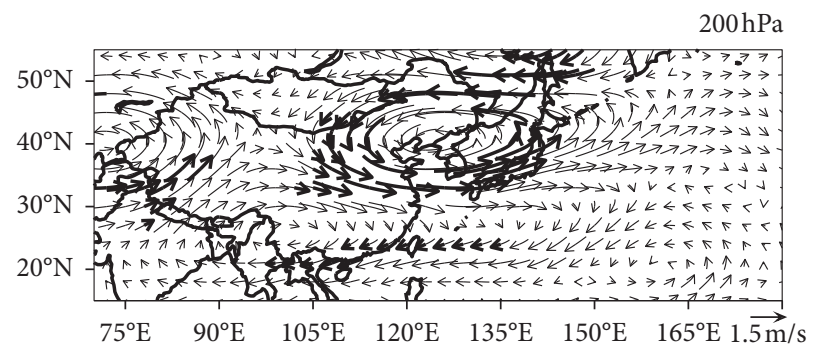

(f)

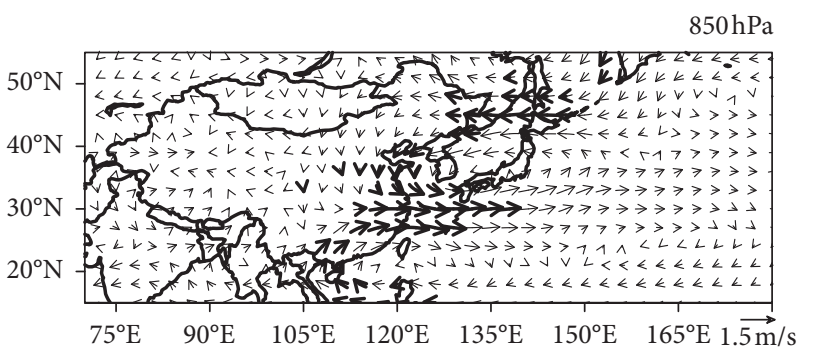

(h)

FIGURE 6: PC2-regressed SSTs in the previous autumn (a), previous winter (b), spring (c), and summer (d) during 1979-1999 (contour interval: 0.1). Previous autumn and winter denote the seasons before one year, which means the PC2-regressed SSTs in autumn and winter between during 1978-1998, respectively. PC2-regressed geopotential height and horizontal winds in boreal summer during 1979-1999 at $200 \mathrm{hPa}(\mathrm{e}, \mathrm{f})$ and $850 \mathrm{hPa}$ (g, h). Solid (dashed) contours denote positive (negative) anomalies, and thick solid lines denote zero. Red (blue) color shadings from light to dark indicate statistical significance at the $90 \%, 95 \%$, and $99 \%$ levels. Contour intervals are 5 gpdm in (e) and 2 gpdm in (c). Thick vectors in (f) and (h) denote statistical significance at the $95 \%$ confidence level.

development from the previous winter to summer during 1979-1999, which nevertheless becomes weak during 2000-2016. This finding enlightens us to separate the eastern-type ENSO events from other ENSO events and investigate the impact of occurrence frequency of easterntype ENSO events. To quantitatively examine the variability of the occurrence rate of EP-type ENSO, we calculate the EP-type index $I_{\text {EPI }}$ from 1979 to 2016 (Figure 10). EP-type El Niño events occurred in 1982/1983, 1986/1988, 1991/ 1992, 1997/1998, and 2015/2016, and EP-type La Niña events in 1984/1986, 1988/1989, 1999/2000, 2007/2008, and 2010/2011. There were seven EP-type ENSO events during 1979-1999 compared with three during 2000-2016 (Table 1), reflecting the regime shift of EP-type ENSO in the 1990s [59-61]. The average occurrence rate of the EP-type events is once every $\sim 3$ years during 1979-1999, and this reduces to about once every 5.7 years during 2000-2016. This suggests that PC2 variability during 1979-1999 is positively associated with the occurrence frequency of EPtype ENSO. 


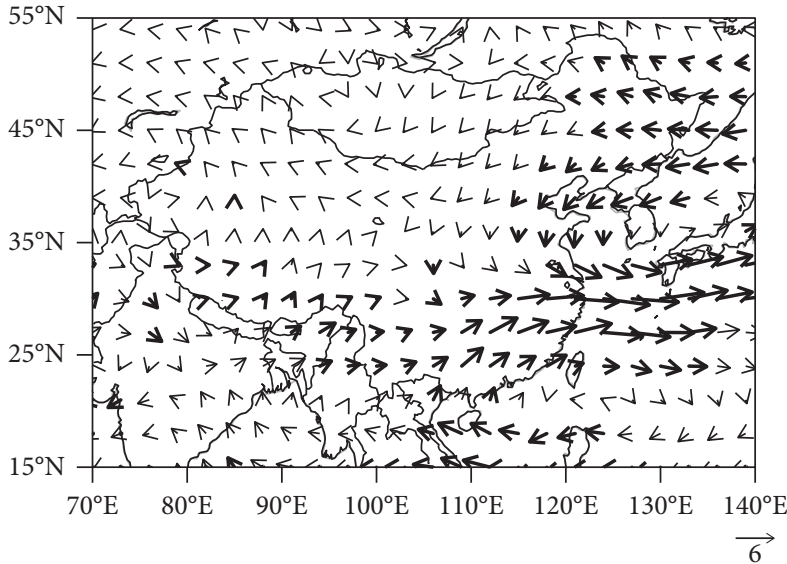

(a)

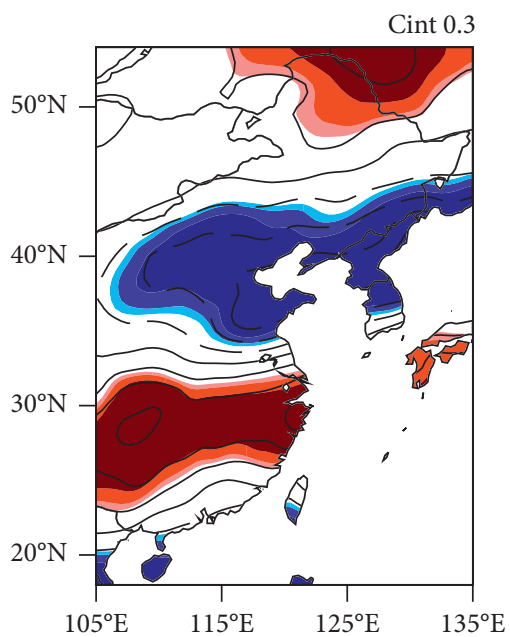

(c)

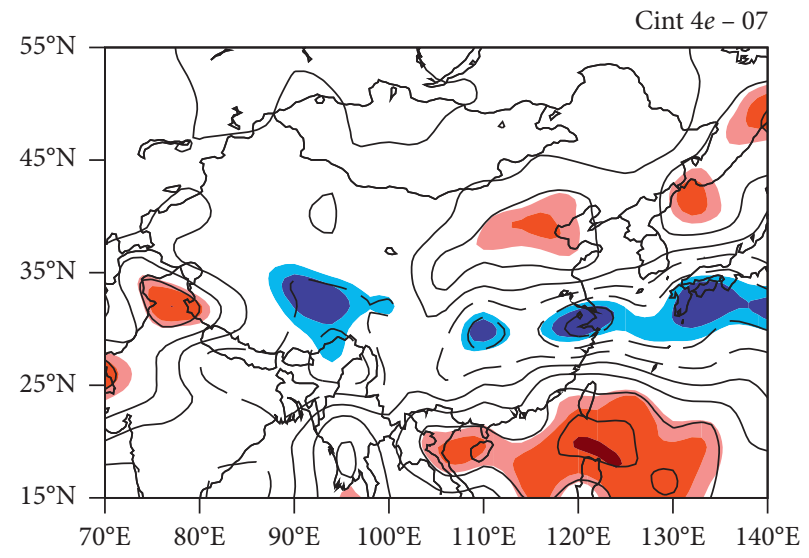

(b)

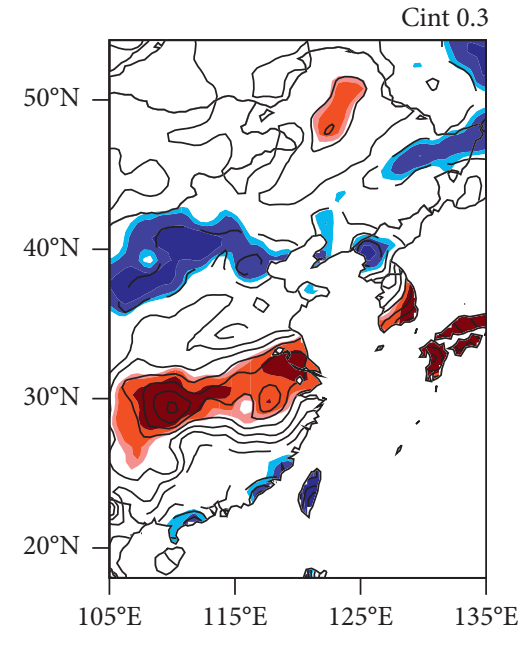

(d)

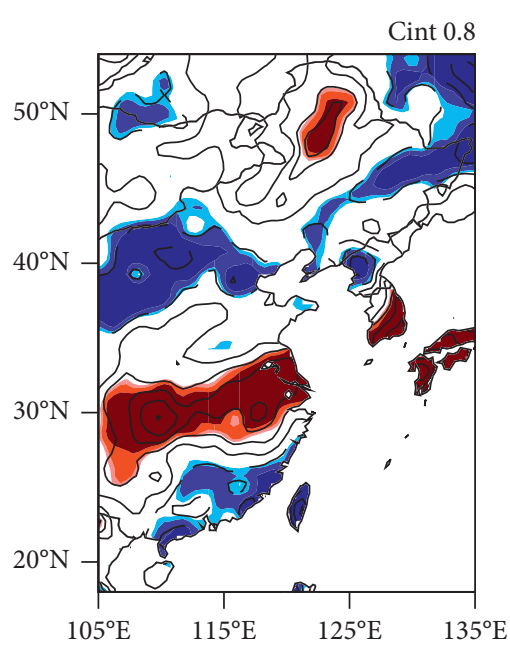

(e)

FiguRe 7: PC2-regressed column-integrated water vapor flux (a) and its divergence (b), total precipitable water (c), precipitation (d), and precipitation efficiency (e) in boreal summer during 1979-1999. Thick vectors in (a) denote the significant areas at the 95\% level. Solid (dashed) contours denote positive (negative) anomalies, and red (blue) color shadings from light to dark for significant areas at 90\%, 95\%, and 99\% levels.

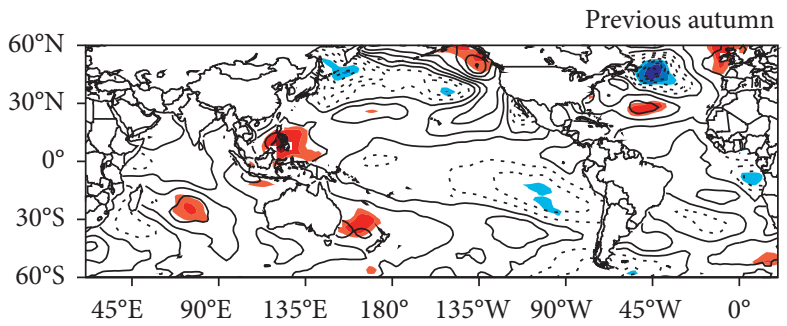

(a)

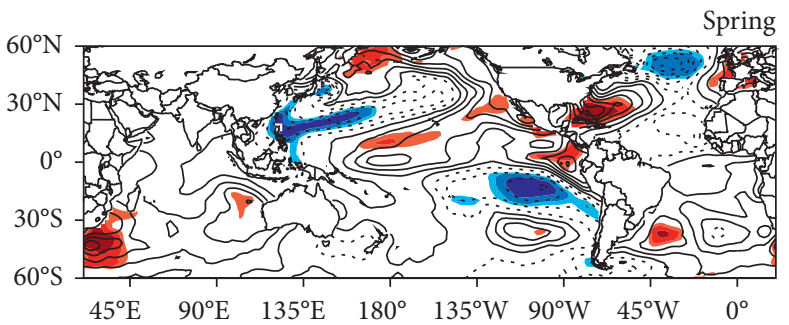

(c)

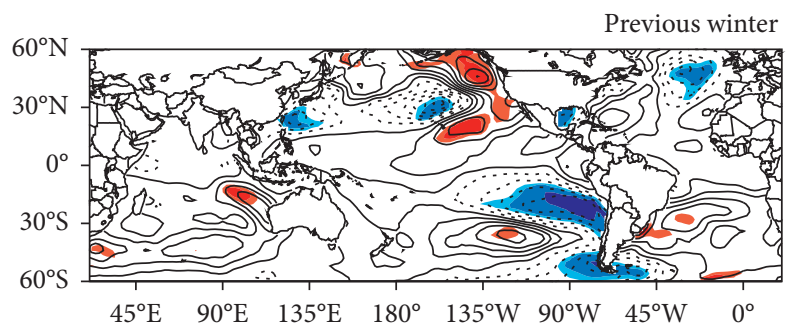

(b)

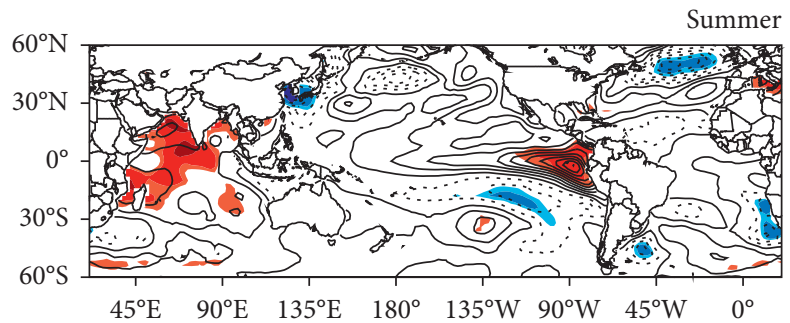

(d)

FIgure 8: Continued. 


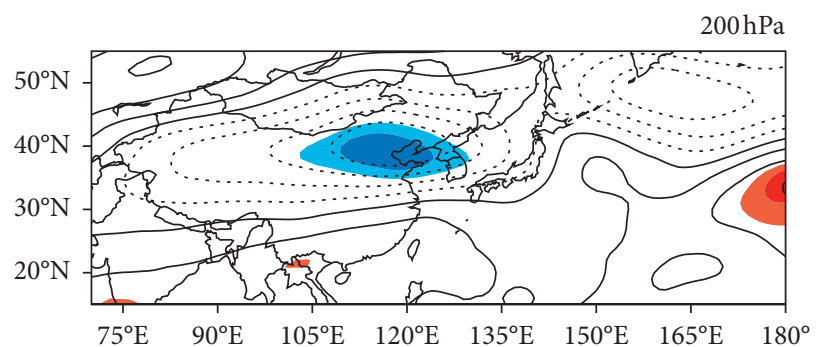

(e)

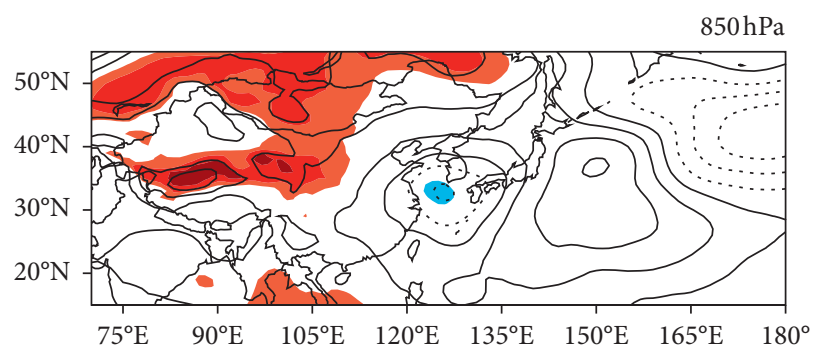

(g)

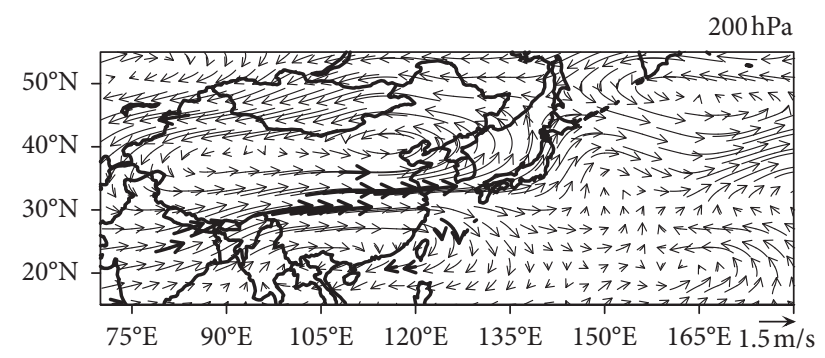

(f)

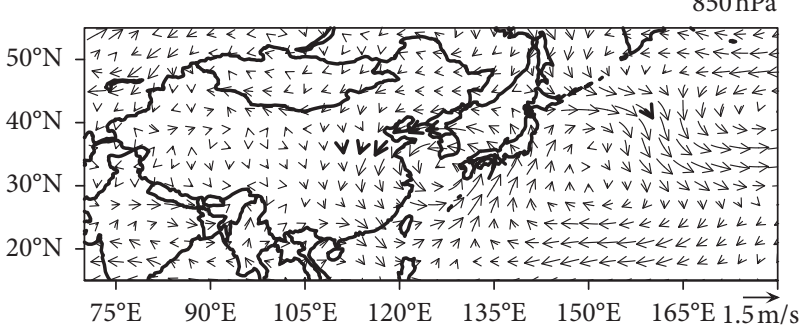

(h)

FIgURe 8: PC2-regressed SSTs in the previous autumn (a), previous winter (b), spring (c), and summer (d) during $2000-2016$ (contour interval: 0.1). Previous autumn and winter denote the seasons before one year, which means the PC2-regressed SSTs in autumn and winter between during 1999-2015, respectively. PC2-regressed geopotential height and horizontal winds in boreal summer during 2000-2016 at $200 \mathrm{hPa}(\mathrm{e}, \mathrm{f})$ and $850 \mathrm{hPa}(\mathrm{g}, \mathrm{h})$. Solid (dashed) contours denote positive (negative) anomalies, and thick solid lines denote zero. Red (blue) color shadings from light to dark indicate statistical significance at the $90 \%, 95 \%$, and $99 \%$ levels. Contour intervals are 5 gpdm in (e) and 2 gpdm in (c). Thick vectors in (f) and (h) denote statistical significance at the $95 \%$ confidence level.

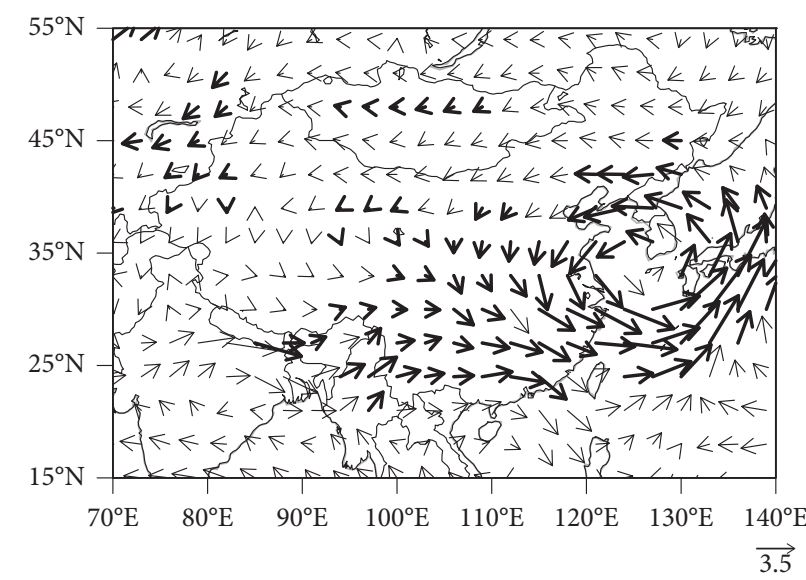

(a)

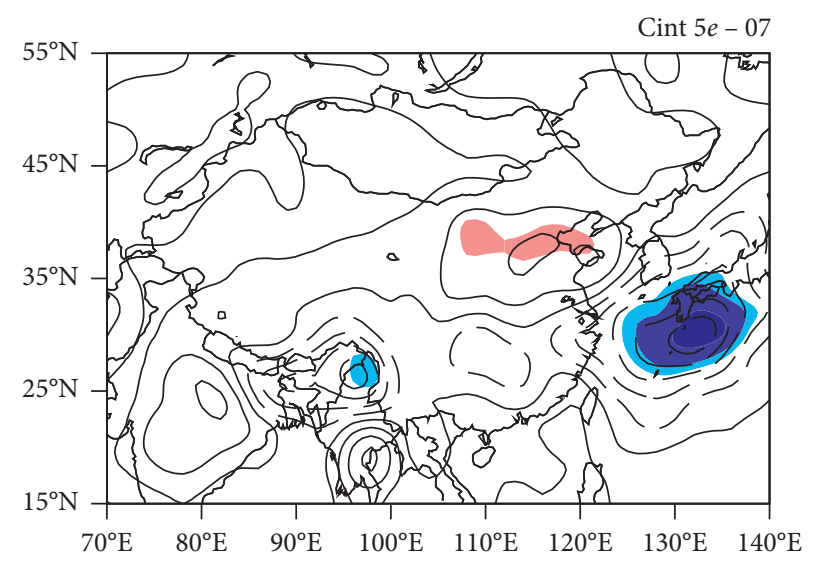

(b)

Figure 9: Continued. 


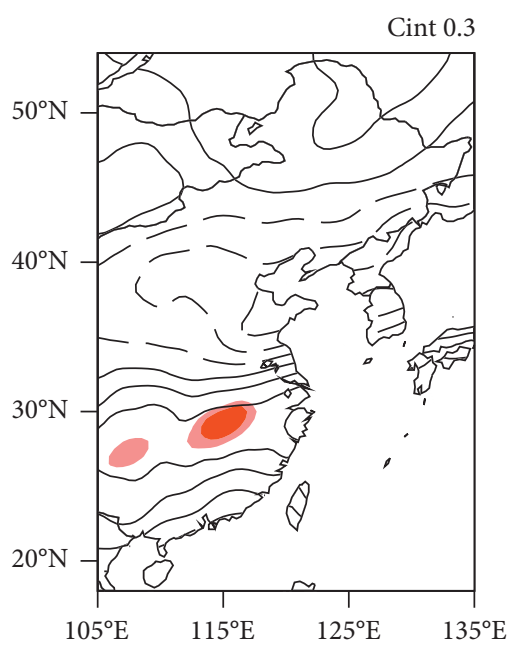

(c)

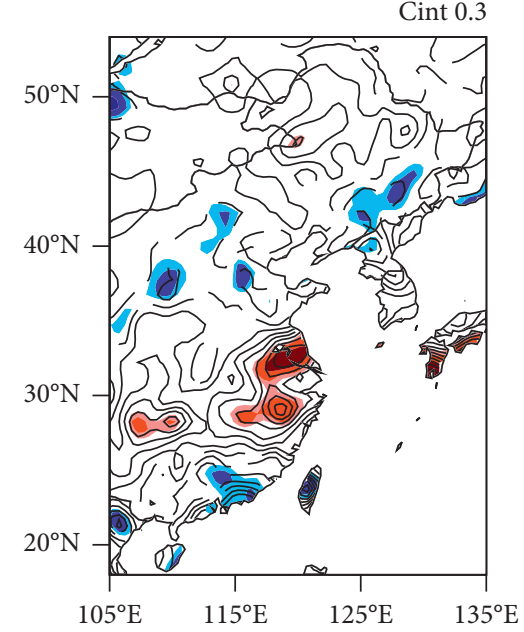

(d)

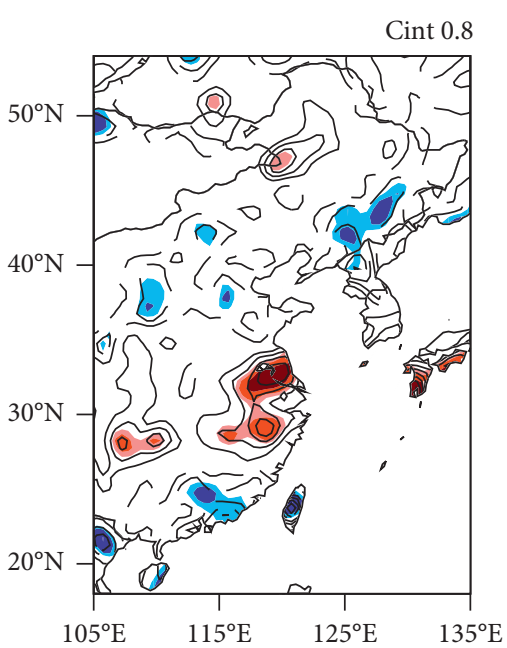

(e)

FIGURE 9: PC2-regressed column-integrated water vapor flux (a) and its divergence (b), total precipitable water (c), precipitation (d), and precipitation efficiency (e) in boreal summer during 2000-2016. Thick vectors in (a) denote the significant areas at the 95\% level. Solid (dashed) contours denote positive (negative) anomalies, and red (blue) color shadings from light to dark for significant areas at $90 \%, 95 \%$, and $99 \%$ levels.

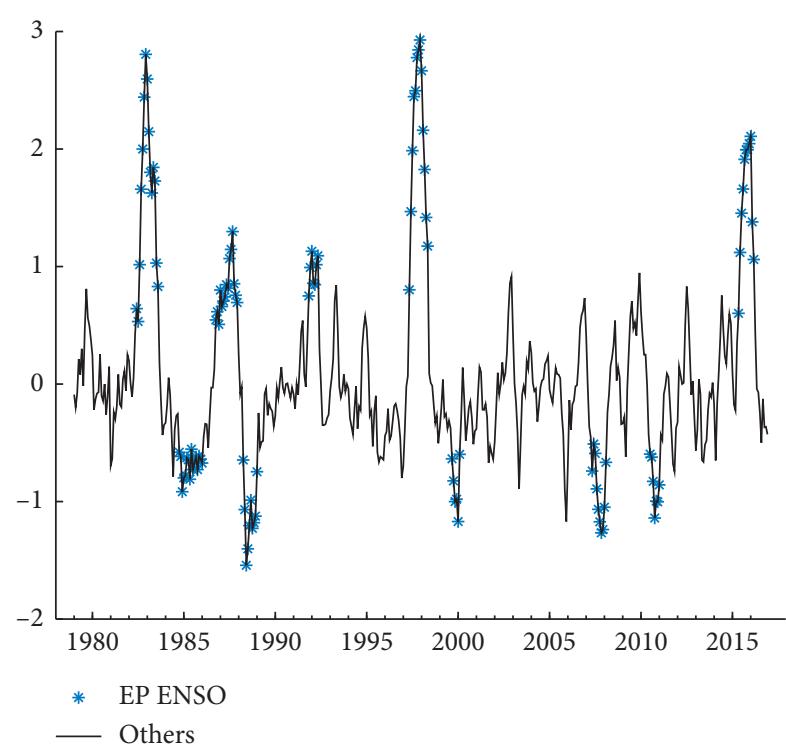

Figure 10: Monthly EP-type ENSO index $\left(I_{\text {EPI }}\right)$ during 1979-2016. The blue asterisks denote the time points of selected EP-type ENSO events.

TABLE 1: EP-type ENSO events during 1979-1999 and 2000-2016.

\begin{tabular}{ccc}
\hline Time period & Number & Years \\
\hline & 1 & $1982 / 1983$ \\
& 2 & $1984 / 1986$ \\
$1979-1999$ & 3 & $1986 / 1988$ \\
& 4 & $1988 / 1989$ \\
& 5 & $1991 / 1992$ \\
& 6 & $1997 / 1998$ \\
$2000-2016$ & 7 & $1999 / 2000$ \\
& 1 & $2007 / 2008$ \\
& 2 & $2010 / 2011$ \\
& 3 & $2015 / 2016$ \\
\hline
\end{tabular}

\section{Conclusions and Discussion}

This study investigated the climatology and IDV of PE in East Asia during summer over the period 1979-2016. The PE climatology shows distinct regional characteristics with an overall decrease in value from coastal to inland areas. The standard deviation of $\mathrm{PE}$ also shows marked regional differences, with large variability around the western Sichuan basin, southeast coast of China, Northeast China, and the eastern part of the Russian Far East and weak variability in the southern and western parts of the Mongolian Plateau. The results suggest that PE variability is affected mainly by precipitation variability.

The EOF analysis of PE has revealed two major modes of IDV, where PC1 represents changes in mean value and PC2 corresponds to transitions of the variability. The PC1 IDV changed during 1998-1999, with a meridional negativepositive dipole pattern during 1983-1998 and the opposite dipole distribution during 1999-2011. The PC2 IDV changed during 1999-2000 with a prominent negativepositive-negative-positive quadrupole structure during 1979-1999 and a much weaker structure during 2000-2016.

Research results suggest that the IDV of mean PE is caused by the PDO phase change around 1998-1999. The PDO remains in a cool phase during 1983-1998 and then shifts to a warm phase during 1999-2011. When the PDO is in its cool phase, there are warm SST anomalies in the Northwest Pacific that facilitate the development of an anticyclone over the Mongolian Plateau and a cyclone south of $35^{\circ} \mathrm{N}$. This anomalous atmospheric circulation leads to a decrease in moisture supply and reduces the precipitation in Northeast Asia. Under the dominant influence of rainfall variations, the local PE decreases accordingly. For the same reason, $\mathrm{PE}$ increases in Southeast Asia under the impact of an anomalous cyclone. After the PDO transitions to the warm phase, the opposite dipole pattern with northward 
positive-negative distributions dominates the variations of mean PE.

The IDV of PE variability can be attributed to the frequency of occurrence of EP-type ENSO events. The average occurrence rate of EP-type ENSO is once every 3 years during 1979-1999, much higher than that during 2000-2016 (every $\sim 5.7$ years). Before the regime shift of EP-type ENSO, the SST anomalies force a wave train pattern of geopotential height anomalies, which resemble the East Asia-Pacific (EAP) pattern [72-75]. The associated wind anomalies modulate the moisture transport over the South China Sea, the Jianghuai River Basin, and North China [76, 77]. Under the joint action of precipitation and total precipitable water, $\mathrm{PE}$ variability exhibits a quadrupole pattern with northward negative-positive-negative-positive anomalies covering almost all of East Asia during the EP-type El Niño. The PE variability exhibits the opposite quadrupole pattern during the EP-type La Niña. As the occurrence rate of EP-type ENSO reduces by almost a half after the regime shift, the PE variability pattern becomes almost indiscernible.

It can be inferred from the close relationship between the PE IDV and the Pacific SST anomalies that the interdecadal changes of PE should also be closely related to the East Asian summer monsoon (EASM) activity. According to previous studies, decadal and interdecadal SST variability can affect the multi-timescale variabilities of the EASM and the WPSH $[78,79]$. When the WPSH is strengthened and moves southwestward, the EASM is weakened, which changes the monsoonal precipitation by regulating southwesterly moisture transport $[17,80]$. However, the correlations between the two leading PCs of PE and the EASM index [81] or the WPSH indices [76, 77] are not always significant in different interdecadal periods. This may be ascribed to changes in the relationship between the EASM and the tropical Indian Ocean patterns in which the quasibiennial type ENSO serves as a remote forcing [82]. In the meantime, the coupling of the North Atlantic Oscillation and North Atlantic triple SST anomaly has a large impact on South China summer rainfall through a Eurasian wave-like train [83].

Note that the combined effects of PDO and ENSO also exert a significant impact on $\mathrm{PE}$ and precipitation variabilities in East Asia on interannual to interdecadal timescales [30, 84-87]. For example, the PDO provides a background condition that modulates the ENSO-related SST anomalies over the western North Pacific and the Philippine Sea, which further influence the interannual variability of early summer rainfall in south China by altering the intensity of the subtropical high $[88,89]$. When the ENSO and $\mathrm{PDO}$ are in phase, the early summer rainfall amount over South China tends to be higher or lower than normal [90]. During the El Niño/PDO warm phase, the precipitation and streamflow in the main river basins in China decrease, while the La Niña/PDO cold phase is related to the opposite condition with an overall increase in precipitation over most of China [91]. By investigating the seasonally resolved stalagmite $\delta^{18} \mathrm{O}$ record, Zhang et al. [92] found that the ENSO/ PDO phase changes are also associated with the precipitation seasonality in southeastern China through oceanatmosphere interactions.
The PE is a crucial factor that determines the spatial distribution of precipitation and is important for weather and climate risk analysis and forecasting. This study has revealed that the transitions of the mean value and variability of PE can mainly be ascribed to the PDO phase change and the occurrence frequency of EP-type ENSO events, respectively. However, their impact on the interannual variability and seasonality of PE in East Asia is still poorly understood. In addition, our results are somewhat limited by the statistical methods employed to explore this topic. Since the PDO and ENSO are not linearly independent, their influence on climate variability is usually entangled [93]. Chen and Tung [94] used a novel method of rotated EOF with pairwise rotation of the principal components to extract the modes of global-mean SST from interannual to multidecadal timescales. They found that both PDO and ENSO contribute to the global mean surface temperature variations, in which the impact of ENSO is mainly limited to the interannual timescale, but the effect of the PDO is about a tenth of that of the Atlantic Multidecadal Oscillation. Applying their rotated EOF analysis to $\mathrm{PE}$ can also separate the spacetime information of ENSO and PDO in PE variability on different timescales. Thus, it can help with the investigation of the factors driving $\mathrm{PE}$ variations and determine the key physical processes in future research. It is also necessary to conduct an in-depth analysis of the PE IDV by focusing on the cloud-climate feedback processes in relation to PE variability, including the environmental dynamics and thermodynamics associated with precipitation in convective systems.

\section{Data Availability}

The data used to support the findings of this study are available from the corresponding author upon request.

\section{Disclosure}

The monthly atmospheric reanalysis data are provided by the European Centre for Medium-Range Weather Forecasts (ECMWF). Two versions of monthly mean precipitation data are used in this study: one from the Global Precipitation Climatology Project (GPCP) version 2 and the other from the Global Precipitation Climatology Center (GPCC) version 8 . The monthly SST data are adopted from the Extended Reconstruction SSTs (ERSSTs) version 5 of the National Oceanic and Atmospheric Administration (NOAA).

\section{Conflicts of Interest}

The authors declare that there are no conflicts of interest regarding the publication of this paper.

\section{Authors' Contributions}

Jian Wang and Shu Gui contributed equally to this study.

\section{Acknowledgments}

This work was supported by the National Natural Science Foundation of China (41861144012, 41875103, and 
41975093), the Natural Science Foundation of Yunnan Province (2018FY001-018, 2018FB081, 2018BC007, and 2019FY003006), the Program for Innovative Research Team in Science and Technology at the University of Yunnan Province (2019HC027), and the Natural Science Foundation of the Yunnan Provincial Education Department (2019J0019, 2019Y0013, and 2018Y002).

\section{References}

[1] C. A. Doswell, H. E. Brooks, and R. A. Maddox, "Flash flood forecasting: an ingredients-based methodology," Weather and Forecasting-Weather Forecast, vol. 11, pp. 560-581, 1996.

[2] T. Enomoto, B. J. Hoskins, and Y. Matsuda, "The formation mechanism of the Bonin high in August," Quarterly Journal of the Royal Meteorological Society, vol. 129, no. 587, pp. 157178, 2003.

[3] R. R. Braham, "The water and energy budgets of the thunderstorm and their relation to thunderstorm development," Journal of Meteorology, vol. 9, no. 4, pp. 227-242, 1952.

[4] A. H. Auer and J. D. Marwitz, "Estimates of air and moisture flux into hailstorms on the high plains," Journal of Applied Meteorology, vol. 7, no. 2, pp. 196-198, 1968.

[5] M. Chong, P. Amayenc, G. Scialom, and J. Testud, "A tropical squall line observed during the COPT 81 experiment in West Africa. Part 1: kinematic structure inferred from dual-doppler radar data," Monthly Weather Review, vol. 115, pp. 670-694, 1987.

[6] G. M. Heymsfield and S. Schotz, "Structure and evolution of a severe squall line over Oklahoma," Monthly Weather Review, vol. 113, no. 9, pp. 1563-1589, 1985.

[7] B. Schoenberg Ferrier, J. Simpson, and W.-K. Tao, "Factors responsible for precipitation efficiencies in midlatitude and tropical squall simulations," Monthly Weather Review, vol. 124, pp. 2100-2125, 1996.

[8] G. A. Grell, "Prognostic evaluation of assumptions used by cumulus parameterizations," Monthly Weather Review, vol. 121, pp. 764-787, 1993.

[9] K. M. Lau and H. T. Wu, "Warm rain processes over tropical oceans and climate implications," Geophysical Research Letters, vol. 30, 2003.

[10] C.-H. Sui, X. Li, and M.-J. Yang, "On the definition of precipitation efficiency," Journal of the Atmospheric Sciences, vol. 64, no. 12, pp. 4506-4513, 2007.

[11] T. Mauritsen, B. Stevens, E. Roeckner et al., "Tuning the climate of a global model," Journal of Advances in Modeling Earth Systems, vol. 4, no. 3, 2012.

[12] L. Tomassini, A. Voigt, and B. Stevens, "On the connection between tropical circulation, convective mixing, and climate sensitivity," Quarterly Journal of the Royal Meteorological Society, vol. 141, no. 689, pp. 1404-1416, 2015.

[13] M. Zhao, "An investigation of the connections among convection, clouds, and climate sensitivity in a global climate model," Journal of Climate, vol. 27, no. 5, pp. 1845-1862, 2013.

[14] M. Zhao, J. C. Golaz, I. M. Held et al., "Uncertainty in model climate sensitivity traced to representations of cumulus precipitation microphysics," Journal of Climate, vol. 29, no. 2, pp. 543-560, 2015.

[15] A. Bailey, J. Nusbaumer, and D. Noone, "Precipitation efficiency derived from isotope ratios in water vapor distinguishes dynamical and microphysical influences on subtropical atmospheric constituents," Journal of Geophysical Research: Atmospheres, vol. 120, no. 18, pp. 9119-9137, 2015.
[16] B. Stevens and G. Feingold, "Untangling aerosol effects on clouds and precipitation in a buffered system," Nature, vol. 461, no. 7264, pp. 607-613, 2009.

[17] A. J. Baker, H. Sodemann, J. U. L. Baldini et al., "Seasonality of westerly moisture transport in the East Asian summer monsoon and its implications for interpreting precipitation

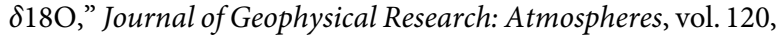
no. 12 , pp. $5850-5862,2015$.

[18] R. Ent and O. Tuinenburg, "The residence time of water in the atmosphere revisited," Hydrology and Earth System Sciences, vol. 21, no. 2, pp. 779-790, 2017.

[19] N. Wang, X.-M. Zeng, Y. Zheng, J. Zhu, and S. Jiang, "The atmospheric moisture residence time and reference time for moisture tracking over China," Journal of Hydrometeorology, vol. 19, no. 7, pp. 1131-1147, 2018.

[20] T. Wang, J.-P. Miao, J.-Q. Sun, and Y.-H. Fu, "Intensified East Asian summer monsoon and associated precipitation mode shift under the $1.5^{\circ} \mathrm{C}$ global warming target," Advances in Climate Change Research, vol. 9, no. 2, pp. 102-111, 2018.

[21] C. Zhang, Q. Tang, D. Chen, L. Li, X. Liu, and H. Cui, “Tracing changes in atmospheric moisture supply to the drying Southwest China," Atmospheric Chemistry and Physics, vol. 17, no. 17, pp. 10383-10393, 2017.

[22] X. Shen and X. Li, "Thermodynamic aspects of precipitation efficiency," in Thermodynamics-Interaction Studies-Solids, Liquids and Gases, IntechOpen, London, UK, 2011.

[23] S. C. Sherwood, R. Roca, T. M. Weckwerth, and N. G. Andronova, "Tropospheric water vapor, convection, and climate," Reviews of Geophysics, vol. 48, no. 2, 2010.

[24] F. Tian, B. Dong, J. Robson, and R. Sutton, "Forced decadal changes in the East Asian summer monsoon: the roles of greenhouse gases and anthropogenic aerosols," Climate Dynamics, vol. 51, no. 9-10, pp. 3699-3715, 2018.

[25] T.-J. Zhou and R.-C. Yu, “Atmospheric water vapor transport associated with typical anomalous summer rainfall patterns in China," Journal of Geophysical Research: Atmospheres, vol. 110, no. 8, 2005.

[26] D. Yihui and J. C. L. Chan, "The East Asian summer monsoon: an overview," Meteorology and Atmospheric Physics, vol. 89, no. 1-4, pp. 117-142, 2005.

[27] Z. Zhu, T. Li, and J. He, "Out-of-phase relationship between boreal spring and summer decadal rainfall changes in southern China," Journal of Climate, vol. 27, no. 3, pp. 1083-1099, 2013.

[28] J. Chen, Z. Wen, R. Wu, Z. Chen, and P. Zhao, "Interdecadal changes in the relationship between Southern China winterspring precipitation and ENSO," Climate Dynamics, vol. 43, no. 5-6, p. 382, 2013.

[29] J. Wei, H. R. Knoche, and H. Kunstmann, "Atmospheric residence times from transpiration and evaporation to precipitation: an age-weighted regional evaporation tagging approach," Journal of Geophysical Research: Atmospheres, vol. 121, no. 12, pp. 6841-6862, 2016.

[30] F. Yang and K.-M. Lau, "Trend and variability of China precipitation in spring and summer: linkage to sea-surface temperatures," International Journal of Climatology, vol. 24, no. 13, pp. 1625-1644, 2004.

[31] M. G. Bosilovich, S. D. Schubert, and G. K. Walker, "Global changes of the water cycle intensity," Journal of Climate, vol. 18, no. 10, pp. 1591-1608, 2005.

[32] I. M. Held and B. J. Soden, "Robust responses of the hydrological cycle to global warming," Journal of Climate, vol. 19, no. 21, pp. 5686-5699, 2006. 
[33] R. Bodnar, T. Azbej, S. Becker, C. Cannatelli, A. Fall, and M. Severs, "Whole Earth geohydrologic cycle, from the clouds to the core: the distribution of water in the dynamic Earth system," Special Paper of the Geological Society of America, vol. 500, pp. 431-461, 2013.

[34] H.-H. Hsu, T. Zhou, and J. Matsumoto, "East Asian, indochina and Western North pacific summer monsoon-an update," Asia-Pacific Journal of Atmospheric Sciences, vol. 50, no. 1, pp. 45-68, 2014.

[35] J. Torti, "Floods in southeast Asia: a health priority," Journal of Global Health, vol. 2, no. 2, Article ID 020304, 2012.

[36] C. Xu, Y. Qiao, and M. Jian, "Interdecadal change in the intensity of interannual variation of spring precipitation over southern China and possible reasons," Journal of Climate, vol. 32, no. 18, pp. 5865-5881, 2019.

[37] K. E. Trenberth, "Atmospheric moisture residence times and cycling: implications for rainfall rates and climate change," Climatic Change, vol. 39, no. 4, pp. 667-694, 1998.

[38] J. Wu, A. D. Del Genio, M.-S. Yao, and A. B. Wolf, "WRF and GISS SCM simulations of convective updraft properties during TWP-ICE," Journal of Geophysical Research: Atmospheres, vol. 114, no. 4, 2009.

[39] T. Ma, W. Chen, D. Nath, H.-F. Graf, L. Wang, and J. Huangfu, "East Asian winter monsoon impacts the ENSOrelated teleconnections and North American seasonal air temperature prediction," Scientific Reports, vol. 8, 2018.

[40] Z. Zuo and R. Zhang, "The anomalies of spring rainfall in eastern China and its relation with tropical Pacific SST and Eurasian snow," Chinese Journal of Atmospheric Sciences, vol. 36, pp. 185-194, 2012.

[41] H. Chen, F. Teng, W. Zhang, and H. Liao, "Impacts of anomalous midlatitude cyclone activity over east Asia during summer on the decadal mode of East Asian summer monsoon and its possible mechanism," Journal of Climate, vol. 30, no. 2, pp. 739-753, 2016.

[42] L. Zhang and T. Zhou, "Drought over East Asia: a review," Journal of Climate, vol. 28, no. 8, pp. 3375-3399, 2015.

[43] J. Li, Z. Wu, Z. Jiang, and J. He, "Can global warming strengthen the east asian summer monsoon?," Journal of Climate, vol. 23, no. 24, pp. 6696-6705, 2010.

[44] D. P. Dee, S. Uppala, S. Adrian et al., The ERA-Interim Reanalysis: Configuration and Performance of the Data Assimilation System Q J Roy Meteor Soc, 2011, https://www.ecmwf. int $/$ node $/ 8946$.

[45] A. J. Simmons, P. D. Jones, V. da Costa Bechtold et al., "Comparison of trends and low-frequency variability in CRU, ERA-40, and NCEP/NCAR analyses of surface air temperature," Journal of Geophysical Research: Atmospheres, vol. 109, no. $24,2004$.

[46] B. Huang, P. W. Thorne, V. F. Banzon et al., "Extended reconstructed sea surface temperature, version 5 (ERSSTv5): upgrades, validations, and intercomparisons," Journal of Climate, vol. 30, no. 20, pp. 8179-8205, 2017.

[47] J. S. Chowdary, S.-P. Xie, H. Tokinaga et al., "Interdecadal variations in ENSO teleconnection to the Indo-Western Pacific for 1870-2007," Journal of Climate, vol. 25, no. 5, pp. 1722-1744, 2011.

[48] C. Guan and M. J. McPhaden, "Ocean processes affecting the twenty-first-century shift in ENSO SST variability," Journal of Climate, vol. 29, no. 19, pp. 6861-6879, 2016.

[49] T. Ogata, S.-P. Xie, A. Wittenberg, and D.-Z. Sun, "Interdecadal amplitude modulation of El Niño-Southern oscillation and its impact on tropical pacific decadal variability," Journal of Climate, vol. 26, no. 18, pp. 7280-7297, 2013.
[50] Y. Xue, T. M. Smith, and R. W. Reynolds, "Interdecadal changes of 30-yr SST normals during 1871-2000," Journal of Climate, vol. 16, no. 10, pp. 1601-1612, 2003.

[51] Q. Yang, Z. Ma, P. Wu, N. P. Klingaman, and L. Zhang, "Interdecadal seesaw of precipitation variability between North China and the Southwest United States," Journal of Climate, vol. 32, no. 10, pp. 2951-2968, 2019.

[52] M. Huang, Y. Hong, H. Xu, and H. Zhou, "The effects of the existence of stratiform cloud on the development of cumulus cloud and its precipitation," Acta Meteorologica Sinica, vol. 45, pp. 72-77, 1987, in Chinese.

[53] C.-H. Sui, X. Li, M.-J. Yang, and H.-L. Huang, "Estimation of oceanic precipitation efficiency in cloud models," Journal of the Atmospheric Sciences, vol. 62, no. 12, pp. 4358-4370, 2005.

[54] X. Li, C.-H. Sui, and K.-M. Lau, "Precipitation efficiency in the tropical deep convective regime: a 2-D cloud resolving modeling study," Journal of the Meteorological Society of Japan, vol. 80, no. 2, pp. 205-212, 2002.

[55] S. B. Feldstein and S. Lee, "Intraseasonal and interdecadal jet shifts in the Northern Hemisphere: the role of warm pool tropical convection and sea ice," Journal of Climate, vol. 27, no. 17 , pp. $6497-6518,2014$.

[56] A. W. Robertson and C. R. Mechoso, "Interannual and interdecadal variability of the South Atlantic convergence zone," Monthly Weather Review, vol. 128, pp. 2947-2957, 2000.

[57] N. Shi, Y. Wang, X. Wang, and P. Tian, "Interdecadal variations in the frequency of persistent hot events in boreal summer over Midlatitude Eurasia," Journal of Climate, vol. 32, no. 16, pp. 5161-5177, 2019.

[58] B. Sun, H. Wang, B. Zhou, and H. Li, "Interdecadal variation in the synoptic features of mei-yu in the Yangtze river valley region and relationship with the pacific decadal oscillation," Journal of Climate, vol. 32, no. 19, pp. 6251-6270, 2019.

[59] L. Wang, P. Xu, W. Chen, and Y. Liu, "Interdecadal variations of the silk road pattern," Journal of Climate, vol. 30, no. 24, pp. 9915-9932, 2017.

[60] H.-L. Ren and F.-F. Jin, "Niño indices for two types of ENSO," Geophysical Research Letters, vol. 38, no. 4, 2011.

[61] E. N. Lorenz, Empirical orthogonal functions and statistical weather prediction, Massachusetts Institute of Technology Defense Doc, Cambridge, MA, USA, 1956.

[62] H. von Storch and F. W. Zwiers, Statistical Analysis in Climate Research, Cambridge University Press, Cambridge, UK, 2002.

[63] D. S. Wilks, Statistical Methods in the Atmospheric Sciences: An Introduction (International Geophysics), Academic Pr Inc., Cambridge, MA, USA, 2nd edition, 2005.

[64] G. R. North, T. L. Bell, R. F. Cahalan, and F. J. Moeng, "Sampling errors in the estimation of empirical orthogonal functions," Monthly Weather Review, vol. 110, pp. 699-706, 1982.

[65] N. Bond, J. Overland, M. Spillane, and P. J. Stabeno, "Recent shift in the state of the north pacific," Geophysical Research Letters, vol. 30, no. 23, 2003.

[66] F. P. Chavez, J. Ryan, S. Lluch-Cota, and M. Niquen, "From anchovies to sardines and back: multidecadal change in the Pacific Ocean," Science, vol. 299, no. 5604, pp. 217-221, 2003.

[67] S. Minobe, "Interannual to interdecadal changes in the Bering Sea and concurrent 1998/99 changes over the north pacific," Progress in Oceanography, vol. 55, no. 1-2, pp. 45-64, 2002.

[68] W. Peterson and F. Schwing, "A new climate regime in Northeast Pacific ecosystems," Geophysical Research Letters, vol. 30 , no. $17,1896$. 
[69] H.-Y. Kao and J.-Y. Yu, "Contrasting eastern-pacific and central-pacific types of ENSO," Journal of Climate, vol. 22, no. 3, pp. 615-632, 2009.

[70] J.-S. Kug, F.-F. Jin, and S.-I. An, "Two types of El Niño events: cold tongue El Niño and warm pool El Niño," Journal of Climate, vol. 22, no. 6, pp. 1499-1515, 2009.

[71] H.-I. Jeong and J.-B. Ahn, "A new method to classify ENSO events into Eastern and Central Pacific types," International Journal of Climatology, vol. 37, no. 4, pp. 2193-2199, 2017.

[72] R. H. Huang and W. Li, "Influence of the heat source anomaly over the western tropical Pacific on the subtropical high over East Asia," in Proceedings of the International conference on the general circulation of East Asia, pp. 40-45, Chengdu, China, April 1987.

[73] H. Li, P. Zhai, Y. Chen, and E. Lu, "Potential influence of the East Asia-Pacific teleconnection pattern on persistent precipitation in South China: implications of atypical Yangtze river valley cases," Weather and Forecasting, vol. 33, no. 1, pp. 267-282, 2017.

[74] R. H. Huang, "Studies on the teleconnections of the general circulation anomalies of East Asia causing the summer drought and flood in China and their physical mechanism," Chinese Journal of Atmospheric Sciences, vol. 14, pp. 108-117, 1990, in Chinese.

[75] T. Nitta, "Convective activities in the tropical Western Pacific and their impact on the Northern Hemisphere summer circulation," Journal of the Meteorological Society of Japan. Ser. II, vol. 65, no. 3, pp. 373-390, 1987.

[76] Q. Mu, S. Wang, J. Zhu, and G. Daoyi, "Variations of the western pacific subtropical high in summer during the last hundred years," Chinese Journal of Atmospheric Sciences, vol. 25, pp. 787-797, 2001.

[77] Q. Y. Zhang and S. Y. Tao, "The anomalous subtropical anticyclone in Western Pacific and their association with circulation over East Asia during summer," Chinese Journal of Atmospheric Sciences, vol. 27, pp. 369-338, 2003.

[78] R. Cai, H. Tan, and H. Kontoyiannis, "Robust surface warming in offshore China seas and its relationship to the East Asian monsoon wind field and ocean forcing on interdecadal time scales," Journal of Climate, vol. 30, no. 22, pp. 8987-9005, 2017.

[79] X. Feng, "Interannual to interdecadal variation of East Asian summer monsoon and its association with the global atmospheric circulation and sea surface temperature," Advances in Atmospheric Sciences, vol. 18, no. 4, pp. 567-575, 2001.

[80] J. Zheng, J. Li, and J. Feng, "A dipole pattern in the Indian and Pacific oceans and its relationship with the East Asian summer monsoon," Environmental Research Letters, vol. 9, no. 7, p. 074006, 2014.

[81] B. Wang and Z. Fan, "Choice of South Asian summer monsoon indices," Bulletin of the American Meteorological Society, vol. 80, no. 4, pp. 629-638, 1999.

[82] S.-Y. Yim, J.-G. Jhun, and S.-W. Yeh, "Decadal change in the relationship between East Asian-Western North Pacific summer monsoons and ENSO in the mid-1990s," Geophysical Research Letters, vol. 35, no. 20, 2008.

[83] J. Chen, Z. Wen, R. Wu, X. Wang, C. He, and Z. Chen, "An interdecadal change in the intensity of interannual variability in summer rainfall over Southern China around early 1990s," Climate Dynamics, vol. 48, no. 1-2, pp. 191-207, 2017.

[84] X. Dong and F. Xue, "Phase transition of the Pacific decadal oscillation and decadal variation of the East Asian summer monsoon in the 20th century," Advances in Atmospheric Sciences, vol. 33, no. 3, pp. 330-338, 2016.
[85] J. Feng and J. Li, "Influence of El Niño modoki on spring rainfall over South China," Journal of Geophysical Research: Atmospheres, vol. 116, no. 13, 2011.

[86] Q. Yang, Z. Ma, and B. Xu, "Modulation of monthly precipitation patterns over East China by the pacific decadal oscillation," Climatic Change, vol. 144, no. 3, pp. 405-417, 2016.

[87] L. Yu, T. Furevik, O. H. Otterå, and Y. Gao, "Modulation of the pacific decadal oscillation on the summer precipitation over East China: a comparison of observations to 600-years control run of Bergen climate model," Climate Dynamics, vol. 44, no. 1-2, pp. 475-494, 2015.

[88] W. Duan, L. Song, Y. Li, and J. Mao, "Modulation of PDO on the predictability of the interannual variability of early summer rainfall over South China," Journal of Geophysical Research: Atmospheres, vol. 118, 2013.

[89] J. Mao, J. C. L. Chan, and G. Wu, "Interannual variations of early summer monsoon rainfall over South China under different PDO backgrounds," International Journal of Climatology, vol. 31, no. 6, pp. 847-862, 2011.

[90] J. C. L. Chan and W. Zhou, "PDO, ENSO and the early summer monsoon rainfall over South China," Geophysical Research Letters, vol. 32, no. 8, 2005.

[91] R. Ouyang, W. Liu, G. Fu, C. Liu, L. Hu, and H. Wang, "Linkages between ENSO/PDO signals and precipitation, streamflow in China during the last 100 years," Hydrology and Earth System Sciences, vol. 11, no. 4, 2014.

[92] H. Zhang, H. Cheng, C. Spötl et al., “A 200-year annually laminated stalagmite record of precipitation seasonality in southeastern China and its linkages to ENSO and PDO," Scientific Reports, vol. 8, no. 1, p. 12344, 2018.

[93] X. Chen and J. M. Wallace, "Orthogonal PDO and ENSO indices," Journal of Climate, vol. 29, no. 10, pp. 3883-3892, 2016.

[94] X. Chen and K.-K. Tung, "Global-mean surface temperature variability: space-time perspective from rotated EOFs," Climate Dynamics, vol. 51, no. 5-6, pp. 1719-1732, 2018. 

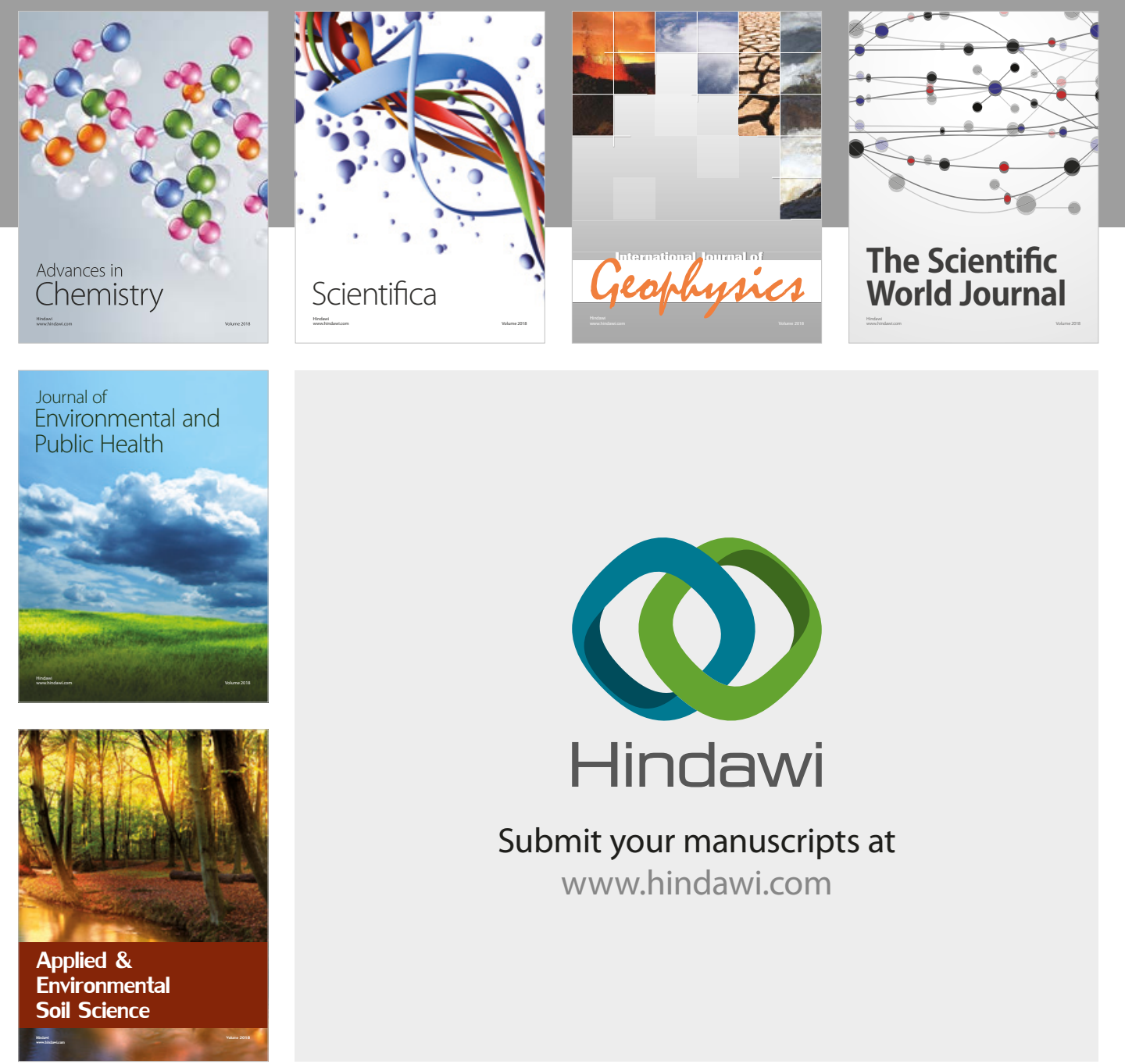

The Scientific

\section{World Journal}
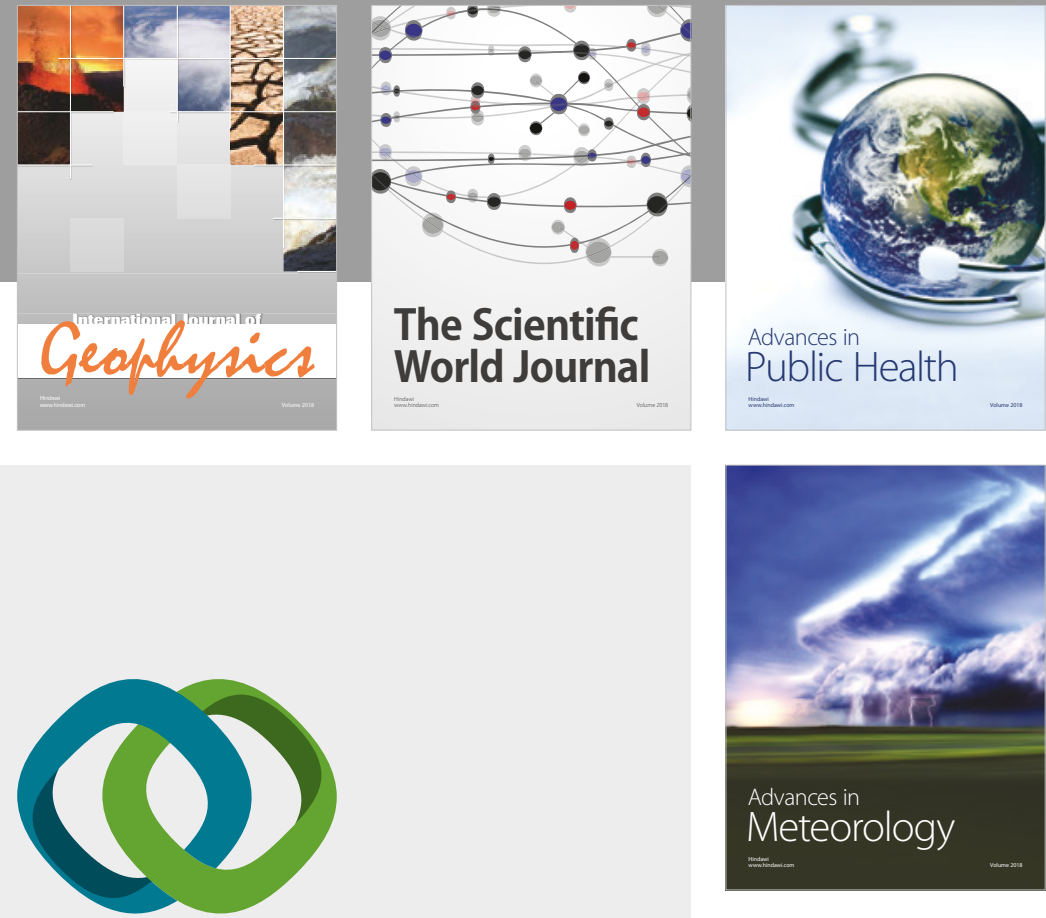

Advan

Public Health

\section{Hindawi}

Submit your manuscripts at

www.hindawi.com
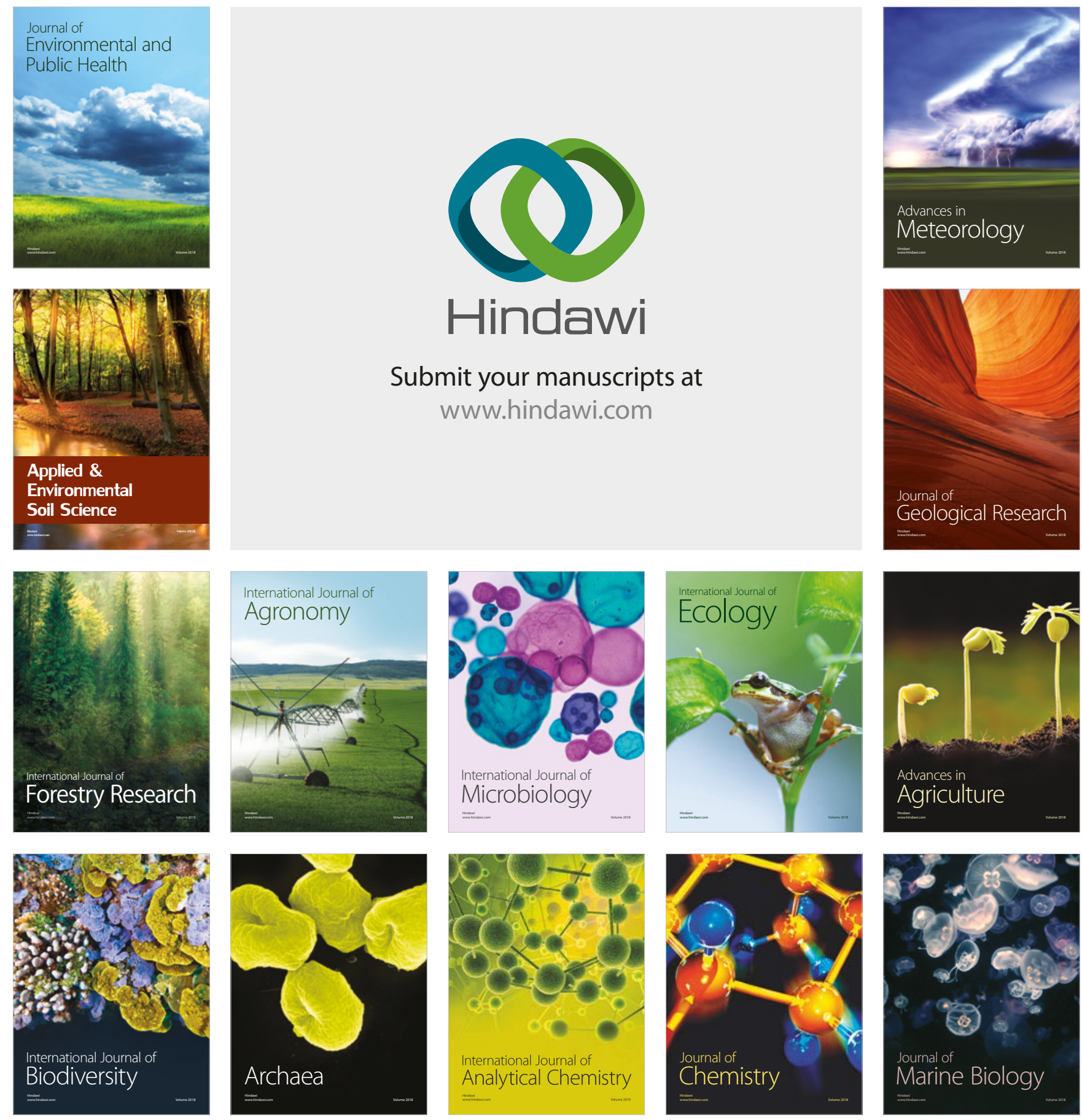